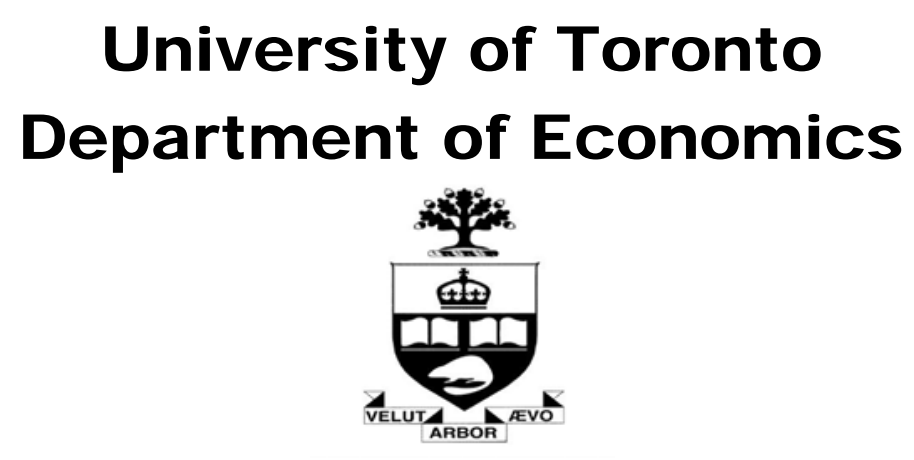

Working Paper 700

In-kind transfers, marketization costs and household specialization: Evidence from Indian farmers

By Nicholas Li

June 25, 2021 


\title{
In-kind transfers, marketization costs and household specialization: Evidence from Indian farmers
}

\author{
Nicholas $\mathrm{Li}^{*}$ \\ University of Toronto
}

June 25, 2021 - Version 1

\begin{abstract}
I examine the effect of in-kind staple transfers on agricultural production in a setting where transactions with markets are costly for households and result in interlinked consumption and production decisions. I leverage the expansion of India's Public Distribution system between 1993-2009 as a natural experiment generating variation in the quantity and value of staple grains transferred to households and districts. I find that larger PDS quantities are associated with modest decreases in staple production and farming and modest increases in market/comparative advantage oriented specialization, with larger effects for households and districts with higher market transaction costs or less market-oriented agriculture.
\end{abstract}

*Thanks to David Atkin, Gustavo Bobonis, Loren Brandt, Lorenzo Caliendo, Pamela Campa, Kala Krishna, Jessica Leight, Diego Restuccia, Andres Rodriguez-Clare, Trevor Tombe, Dan Trefler, MuJeung Yang, Xiaodong Zhu, and seminar participants at the University of Toronto, Ryerson, UCLA, Calgary, Dalhousie, the World Bank, and the CIREQ, NEUDC and Stanford IGC/CGID conferences. Palermo Penano, Ayesha Ali, Jan Victor Dee, Mia Giuriato, David Walker-Jones, Poli Natama and Christopher Sims provided outstanding research assistance. Thanks to Scott Fulford and Treb Allen for sharing their data. All errors are my own. Email: nickli2001@gmail.com 


\section{Introduction}

Low agricultural productivity combined with a large share of households engaged in farming is a common features of developing countries. Many rural households devote a substantial portion of their inputs to producing food crops for their own consumption, with self-produced staple foods making up an important part of their consumption basket. One reason poor households may choose to devote considerable resources to food production is the presence of output market frictions that make it welfare maximizing to forgo market exchange and instead dedicate resources to producing food intended mainly for own consumption. These frictions may take many forms - travel and search costs, retail markups over farm-gate prices, price volatility or the absence of markets on both the buyer and seller side - but these "marketization" costs between household and the market can, like trade costs between markets, link consumption and production decisions and lower the gains from specialization. Figure 1 shows that consumption out of home production plays a large role in the Indian economy, with over $12 \%$ of aggregate consumption sourced out of home production in 1993. Almost $46 \%$ of aggregate food consumption is sourced out of home production for Indian farmers who make 1/4 of all households in 1993. While consumption out of home production has fallen over time, alongside the share of households engaged in farming and the budget share of food, it remains high as late as 2009-2010 and is higher in other developing countries.

An important and unexplored implication of this link between food consumption and household production is that policies targeting household consumption can affect agricultural production and specialization patterns. In particular, policies like subsidies that incentivize consumption of staple foods from market or government sources may lower the incentives of poor rural households to devote inputs to staple production, leading to exit from farming and/or re-allocation of inputs towards crops with higher market exchange value and lower consumption value. An important example of such a policy is India's Public Distribution System (PDS), a central pillar of India's welfare state and the largest in-kind transfer system in the world. The PDS in its present form provides highly subsidized rice and wheat - India's main dietary staples - to poor households through a government managed system of procurement and distribution. Figure 2 shows that both the quantity and size of the PDS subsidy increased considerably between 1993 and 2009, with PDS quantity per capita doubling and the total implicit subsidy value of the transfer (the difference between the 
price paid and the cost of purchasing the same quantity at market prices) more than doubling to reach over $2 \%$ of aggregate expenditures and $8 \%$ of aggregate expenditures for the households that use the system by 2009.

In this paper, I explore the extent to which expansion of PDS entitlements during the 1993-2009 period affected agricultural production and specialization decisions by households and whether variation in the marketization costs linking household consumption needs and production decisions played an important mediating role. I combine data from multiple sources - household consumption data from the National Sample Survey, household production data from ARIS/REDS, and districtlevel production data compiled by ICRISAT - to analyze PDS expansion at the individual and district level and provide insight into the magnitudes of partial and (district-level) general equilibrium effects. The context of PDS expansion is important for my analysis as the 1993-2009 period witnessed the transition from a universal PDS to a "targeted" PDS aimed at devoting more resources to poor households. Entitlements expanded in several stages along multiple margins - quantity, subsidy value per unit, and household eligibility - and there was large variation across states in both the initial level and the expansion of de jure and de facto entitlements over time. I combine this plausibly exogenous variation in entitlements with data on proxies for marketization costs and household production-consumption linkages to provide novel insights that are relevant for the Indian context as well as broader debates about in-kind versus cash transfers and sources of agricultural inefficiency in developing countries.

In the first step of my analysis, I present several relevant facts about the rural Indian setting including the importance of consumption out of home production for the average Indian farmer and the fact that smaller farmers have land portfolios that are systematically skewed towards staple grains and crops with high home consumption value and away from crops with higher market value relative to larger farmers in the same village. Agricultural specialization increases modestly in India between 1993-2009 and this was partly driven by a reduction in the share of land devoted to cereal crops in districts that were not highly specialized in these crops to begin with. I show that marketization costs are likely to be large given the magnitude of price differences between market purchase prices and selling prices for food products within a district. The magnitude of these buying/selling price-gaps are comparable to price differences across district markets and show little evidence of declining over time. 
The data suggest that there are large differences in marketization costs across districts, as district-level proxies for marketization costs, such as local road density and access to rural credit, are highly correlated with the share of rural households that farm, the home-produced share of food consumption, and the extent to which land is allocated based on exogenous relative crop productivity.

These facts motivate a simple partial equilibrium model featuring marketization costs and household consumption-production linkages that I use to derive the implications of a transfer scheme like the PDS. In the model, households have exogenous productivity across three sectors - staple agriculture, market agriculture, and nonagricultural market production - and staples are a necessary but not inferior good. Marketization costs drive a wedge between the opportunity cost of acquiring staples through production versus market exchange and distort the allocation of inputs away from agricultural and non-agricultural activities and towards staple farming which may have a lower market return. Transfers to the household have no effect on production absent marketization costs, but with marketization costs they lead some households to re-allocate inputs. The model highlights the opposite effects of changes in the quantity and per unit subsidy for a scheme like the PDS. Increases in quantity lower incentives for staple crop production, but increases in per unit subsidies act like cash transfers and counter-intuitively increase staple production when staples are a normal good. The model shows the conditions under which we would expect to see larger effects of an increase in transfer quantity, e.g. smaller and less productive farmers and/or those facing higher marketization costs. I outline how general equilibrium effects from PDS expansion, operating through changes in the selling or buying price of staples, could further magnify the direct effect of PDS receipt given differences in the intensity of PDS expansion across locations.

My empirical analysis builds on and largely confirms the insights of the model, moving systematically from evidence on partial equilibrium household-level consumption and production effects (comparing households in the same village) to districtlevel general equilibrium outcomes like prices, output and agricultural specialization. The consumption data show that higher PDS quantities increase overall rice/wheat consumption (0.20-0.31 KG per KG of PDS grains) while crowding out market purchases (0.37-0.46) and consumption out of home production (0.23-0.44). Increases in the PDS per unit subsidy have the opposite effect on consumption from home production as predicted by the model under positive marketization costs. Evidence from 
household production data indicates that increases in the overall value of PDS entitlements between 1999 and 2006 led on average to small re-allocations of land away from staples and crops with high consumption value and towards crops with high market value, as well as decreasing labor inputs on the farm. These average effects are mostly driven by households with high initial shares of agricultural output consumed and/or low land holdings. Households that initially consume a high share of their agricultural output (70\%) decrease their share of land allocated to grains by 0.6 to 12.6 percentage points depending on the specification and increase their net agricultural income by 1.1 to $3.2 \%$. I find minimal evidence that these effects are due to other government interventions during this period that could be correlated with PDS expansion for poor households.

Turning to the district-level analysis, I find that PDS expansion modestly lowered average market purchase prices for rice and wheat (2.4-4.2\%) but had much weaker effects on seller prices, likely due to some combination of relative openness of wholesale markets across Indian districts and direct intervention by the government through PDS procurement and minimum support prices for farmers. Despite the lack of effect on seller prices, I find that rice and wheat production decreased moderately due to increases in PDS quantity, falling by 0.054 to $0.094 \mathrm{KG} /$ per capita/month in response to a $1 \mathrm{KG} /$ per capita/month increase in PDS quantity. These decreases in staple output are accompanied by district-level decreases in the share of rural households deriving their main income from farming, decreases in the home-produced share of food for farmers, and land re-allocation towards crops in which the district has exogenous (agro-ecological) comparative advantage relative to the rest of India. Overall the PDS expansion between 1993 and 2009 accounts for about 30\% of the decline in the share of rural households classified as farmers and $20 \%$ of the decline in the share of food consumed out of home production. For rice output and other specialization measures, the effect of PDS expansion is mostly driven by districts with high marketization costs, proxied by above median home-produced share of food for farmers or below median road density or rural bank branches. My main results are robust to controlling for district trends or common state-level shocks. Overall, the evidence from both household and district level data provide strong support for the hypothesis that the beneficiaries of PDS expansion between 1993-2009 re-allocated their land and labor inputs away from staple production, with most of these effects driven by households with strong consumption-production linkages due to the com- 
bination of low income and high marketization costs.

This paper builds on three lines of research on agricultural household models, agricultural misallocation due to domestic trade and input market frictions, and the effects of cash and in-kind transfers on poor households. The classic literature on agricultural household models, much of it reviewed in Singh et al. (1986), de Janvry et al. (1991), Taylor and Adelman (2003) and de Janvry and Sadoulet (2006), recognized that consumption and production decisions of agricultural households are linked through transaction costs and market failures, leading to behavior that appears inefficient from a market perspective but that is welfare maximizing for the household. Much of this literature, particularly recent empirical contributions, focuses on input markets and input allocations (e.g. LaFave and Thomas (2016), Foster and Rosenzweig (2021)). Several studies consider output choices and particularly the link between risk, household credit and insurance, and riskier crop choices (Fafchamps (1992), Karlan et al. (2014)). The most closely related papers in this literature by Omamo (1998), Morando (2020b) and Morando (2020a) also observe that even without risk, high costs of transacting with markets can lead poor households to allocate more land to staple crops instead of market-oriented crops. I contribute to this literature by considering a novel implication of non-separable agricultural household models - the allocation of household inputs to staple production can be affected by in-kind staple transfers. My analysis also highlights the usefulness of the home produced share of consumption, a widely available but underutilized measure of market integration at the household level, for empirical analysis.

My paper also contributes to the literature on domestic trade and market frictions in agriculture that lower aggregate efficiency. A number of papers have used quantitative trade models to explore how domestic trade frictions can prevent gains from crop specialization using static models (Donaldson (2018), Sotelo (2020), Adamopolous (2020)) and extensions that incorporate risk and volatility (Allen and Atkin (2016)) and non-homothetic preferences (Rivera-Padilla (2020)). Several papers delve more deeply into the nature of these frictions, including the role of intermediaries, competition, and markups (Atkin and Donaldson (2015), Chatterjee (2020), Bergquist and Dinerstein (2020)) and information frictions (Allen (2014)) in generating price differences in the internal market. Macro models featuring heterogeneous agricultural production units and input misallocation have drawn attention to the low productivity of small farms and potential gains from re-allocating inputs to larger farmers 
(Adamopolous and Restuccia (2014), Adamopolous et al. (2019), Adamopolous et al. (2019), Adamopolous and Restuccia (2020), Aragon et al. (2020), Gollin and Udry (2021)). Macro structural change models emphasize the link between non-homothetic demand for agricultural output (food in particular) and the potential gains from reallocating workers away from low productivity agriculture (Restuccia et al. (2008), Lagakos and Waugh (2013), Gollin et al. (2014), Hamory et al. (2017) and Pulido and Swiecki (2020)). Some papers in this literature feature a prominent role for output or input market frictions between rural and urban sectors (Gollin and Rogerson (2014)) or countries (Tombe (2014)). My contribution is to show that many of these issues at the nexus of non-homotheticity, crop choice, inputs allocated to agriculture, and output market frictions operate at the level of household to market interactions, not just between regional markets or sectors. When consumption and production decisions are linked at the household level, assuming representative consumers or homogeneous output across production units could miss an important piece of the low agricultural productivity puzzle in developing countries. My findings suggest that output market frictions between household and market could be as important as trade costs between markets when it comes to crop specialization patterns or inputs into agriculture, and that policies affecting the "consumption advantage" of staple farming for poor rural households can have important effects on their production.

Finally, my paper relates to a large literature on the effects of India's Public Distribution System specifically and the effects of cash and in-kind transfers on rural households more generally. Most of the literature on India's PDS has focused on evaluating its effects on consumption, nutrition, and poverty (Tarozzi (2005), Kochar (2005), Dreze and Khera (2013), Krishnamurthy et al. (2014), Kaushal and Muchomba (2015), Basu and Das (2014)). Recent papers byGardenne (2020) and Gardenne et al. (2021) explore in more detail how the specific features of the PDS (i.e. quantity rationing and the subsidy and insurance value of PDS prices) affect household welfare and how they compare to other potential mechanisms for helping poor households (see also Khera (2011a) for survey evidence on why many Indian households say they prefer the existing PDS system to cash transfers). I am not aware of any previous studies that consider production-side effects of PDS and the PDS expansion I analyze here, so this paper addresses an important gap in the literature on the world's largest in-kind transfer program and one of the pillars of India's welfare state.

In the broader literature on in-kind transfers, Currie and Gahvari (2008) survey 
the theoretical rationales for in-kind transfers, concluding that paternalism is likely the dominant explanation in developed countries but noting that pecuniary effects may play some role (e.g. distributing food as a form of support to farmers, general equilibrium effects on prices). The empirical evidence for effective paternalistic transfers in developing countries is mixed and several studies find zero or minor effects when comparing cash and in-kind or voucher transfers (Cunha (2014), Sivakul (2012), Sivakul (2017)). Cunha et al. (2019) highlight the relevance of pecuniary effects for developing countries - cash and in-kind transfers can have different effects on local prices when markets are not well integrated. They show that in remote villages in rural Mexico cash transfers can raise food prices and in-kind food transfers can lower food prices. This is interesting in light of the survey evidence suggesting that poor households in developing countries often prefer in-kind to cash transfers, particularly when they have trouble accessing markets (Khera (2011a), Ghatak et al. (2016), Hirvonen and Hoddinott (2021)). Consistent with the evidence in Cunha et al. (2019) I find evidence of negative effects on local market prices from in-kind transfers, but I also highlight the different partial equilibrium effects of cash and in-kind food transfers for individual households and the implications for production in a setting where most households engage in agricultural production and costs of transacting with markets are high. My findings on agricultural production thus complement the large literature on cash transfers by providing more evidence on the circumstances under which we may expect similar or different effects from infra-marginal in-kind transfers. An important element of the PDS is that the program has a long history and strong political support, which may lead to more durable changes in production behavior than cash transfer programs that are either new and politically vulnerable or the result of NGO/academic experiments, particularly for decisions like crop allocations or land transactions that feature switching costs or irreversibility. Although I cannot directly compare cash versus in-kind transfers with my data, my analysis highlights important differences between changes in PDS quantities and changes in the implicit per unit subsidy of the PDS and the latter are theoretically equivalent to cash transfers in my framework.

The rest of the paper is organized as follows. Section 2 describes the data and relevant features of agricultural specialization, marketization costs and PDS expansion in India. Section 3 presents a simple model building on these features to derive predictions for the impact of PDS expansion on agricultural outcomes. Section 
4 presents the empirical results for household consumption, household production, and district-level production effects of PDS expansion. Section 5 offers concluding comments.

\section{Data and context}

\subsection{Data}

The data for Figure 1 and Figure 2 come from India's National Sample Survey (NSS), the most detailed source of data on PDS usage and household consumption patterns. The survey is based on a 30 day recall period and contains household characteristics and detailed consumption data for about 100,000 households in the years used for my analysis (1993-94, 1999-00, 2004-05, and 2009-10). Sampling is based on twostage stratification with first-stage units (villages and city blocks) randomly sampled within a state, and 10-12 households sampled within each first-stage unit. The most disaggregated unit that can be used for panel analysis or geocoded and matched to other data is the district. District boundaries change over time but there are about 300 consistent districts in India using 1966 district boundaries, with a median area of 7500 square kilometers (equivalent to the 116th ranked Metropolitan Statistical Area in the United States).

The consumption survey lists individual items such as rice, wheat, milk, chicken, chick peas, spinach, etc. Households are asked to report the quantity and value of goods consumed and whether they are purchased from the market or produced by the household. 1 While goods purchased through the market are valued at their transaction price, home produced goods are valued at "ex farm or ex factory gate" not including "any element of distributive service charges." In addition to market purchases, beginning in 1993-94 the survey records quantities and values of rice and

\footnotetext{
${ }^{1}$ Goods like refined flour (as opposed to Atta, the wholemeal wheat flour traditionally produced at home, which is what is usually captured by "wheat," including PDS wheat) and bread are not considered home-producible as any subsequent processing of foods by the household is not recorded; these goods are only recorded if they are purchased from the market. My concept of marketization therefore abstracts from the "service" magin of whether to make breads, rice noodles and rice cakes at home or purchase them in the market. This also lowers the importance of quality and product heterogeneity when analyzing prices although there is still scope for quality variation across less processed agricultural commodities. Note that there are some home-producible goods outside of food recorded in the survey - particularly fuel in the form of dung cakes and firewood, but also clothing - but the self-produced consumption shares of these goods are very small.
} 
wheat purchased through the Public Distribution System. ${ }^{2}$

The NSS consumption data provide broad geographic coverage and large sample sizes but provide minimal information on household production - while one can observe consumption out of home production and whether households derive most of their income from self-employment in agriculture, there are no data on agricultural production. I therefore supplement these data with two other sources: the Additional Rural Incomes Survey/Rural Economic \& Demographic Survey (ARIS/REDS) collected by the National Council of Applied Economic Research (NCAER) in 1999 and 2006, and the district-level data set compiled by the International Crops Research Institute for the Semi-Arid Tropics (ICRISAT).

The ARIS/REDS data were designed to constitute a nationally representative sample of rural Indian households and contain detailed economic, demographic, and village level information. The survey records data for almost 5,000 households in over 240 villages across 15 states in each round, and there is a panel component to the survey that allows over 2,000 households to be linked between the 1999 and 2006 rounds. The production data are detailed and include land and inputs allocated to different crops, the division of crop output between sales to the market and home consumption, and income from agricultural and non-agricultural activities. The main limitation of the ARIS/REDS data for the analysis here, other than smaller sample size and coverage, is the lack of data on PDS in the 1999 survey. However, the 2006 survey asks respondents about the value of benefits received from the state for the current and past periods, which allows for an estimate of changes in PDS usage at the household level between the two periods.

The district-level data compiled by ICRISAT as part of the Village Dynamics in South Asia data set come from a variety of state and national level sources. There are about 300 districts defined by consistent 1966 boundaries for the 16 largest states in India and coverage extends to 2009. The data cover land allocations and output for major crops, harvest prices for major crops measured at agricultural wholesale

\footnotetext{
${ }^{2}$ In earlier years of the survey cash, home-produced, and total were recorded separately but in more recent years home production and total are the two categories recorded. In the 1999-00 survey home and market consumption are not recorded separately - instead households were asked whether consumption was out of cash, home, or both. I treat "both" as home production since market purchases are rarely observed for households that have home production in the other data sets. Ownership of ration cards is recorded in 1987-1988 but the source of household rice and wheat purchases is not. Note that other goods are sold through the PDS, most notably kerosene but also sugar in some states, but these are not consumed out of home production and did not undergo a large quantity expansion in the 1990s and I ignore them in my analysis.
} 
markets (mandis), agricultural inputs, the share of households that are primarily engaged in cultivation, and the length of paved roads. There are no data on consumption or PDS usage, but these variables can be constructed at the district level using the NSS data with the caveat that the 1993 NSS data only allow rural areas to be mapped to districts. I supplement these data with district-year level information on highways and travel times between districts (from Allen and Atkin (2016)) and rural bank branches (from Fulford (2013)). I also collect additional data on PDS variables including official state level procurement, allotments, and offtake of PDS grains.

\subsection{Agricultural specialization}

Figure 1 shows a substantial decrease in the aggregate share of consumption out of home production between 1993 and 2009. An important component of this decrease is a decline in the share of food consumption out of own production by "farmers," defined as households whose main source of income is self-employment in agriculture. The typical farmer during this period possesses about 2 hectares of land and spends over half of their budget on food; non-farmer rural households also possess land and consume out of home production but to a much lower degree (Appendix Table A1). Given that households classified as farmers largely decide which crops to grow, staple crops destined for own consumption could be quite important in the overall allocation of agricultural land in India. The decrease in home share of food for farmers is consistent with a shift towards market-oriented agriculture and greater specialization, i.e. households producing crops that earn the highest net return in the market and using the proceeds to purchase staple foods.

While this pattern is suggestive, the home-produced share of food consumption can vary without any implications for production specialization. Even when they produce the same staple crop, farmers with higher output should have a smaller home share of food than farmers with low output because of diminishing returns to staple consumption, leading them to sell more staples to market to purchase other foods. ${ }^{3}$ Even without a change in output, a household fully specialized in rice production could, for various reasons, decide to sell a greater share of the rice they pro-

\footnotetext{
${ }^{3} \mathrm{Li}$ (2021) provides evidence of diminishing returns to quantity for staples in India and also finds that the number of food varieties consumed by Indian households rises in expenditure and over time, both of which could push down the home share unless there is a corresponding increase in the variety of crops produced.
} 
duce at harvest time in exchange for other types of food, processed rice products, or market rice purchased at a later date. ${ }^{4}$ To assess the link between household consumption preferences and production decisions, I turn to production data.

The ARIS/REDS data provides the complementary production-side view of rural Indian households. Figure 3 Panel A shows that in 1999, in addition to consuming a higher share of crop output, households with less land devote a considerably higher share of their land to staple production. The main staples are rice and wheat depending on the region, while a broader definition of staple includes a few other grain crops that are important in terms of land area and share of output consumed at home (maize, millet, sorghum, and barley). Some of these other staples (or "coarse grains") are potentially inferior goods with lower income elasticities than rice and wheat. Consistent with this we see a steeper decline in the share of output consumed for all major grains than rice and wheat only. Importantly, this pattern holds when looking within village (Panel B), so it is not a feature of smaller farmers sorting into villages with land better suited for staple crops.

To assess more systematically how farmers allocate land to crops with different home consumption or market valuations, I construct farmer-level measures that weight the land allocated to different crops by crop-level characteristics. I construct a "consumption crop index" for farmer $i$ as $\sum_{c}$ landshare $_{i c}$ homeshare $_{c}$ where homeshare ${ }_{c}$ is the aggregate share of crop $c$ that is consumed at home in my sample and landshare ${ }_{i c}$ captures each farmer's idiosyncratic land-allocation to that crop. The index is bounded between 0 (for a farmer who only allocates land to crops that never consumed by the household) and 1 (for a farmer who only allocates land to a hypothetical crop that is never sold to the market). I also construct a "market value crop index" as $\sum_{c}$ landshare $_{i c}$ (value/acre) $)_{c v}$ where (value/acre) $)_{c v}$ is the average gross value of crop output per acre for crop $c$ in village $v$ - I calculate values at the village level to allow for differences in yields and prices across locations. Figure 3 Panel B shows that within the same village, the consumption crop index falls with land size while the market value crop index rises.

At the macro-level, there is a modest but clear trend towards increasing crop specialization in India during this period. Figure 4 uses the district-level ICRISAT

\footnotetext{
${ }^{4}$ Seasonality plays a modest role in home shares and is higher around peak harvest periods as expected (Appendix Figure A1). My analysis aggregates household across four consecutive quarters and ignores seasonality but some of my findings are likely to be stronger or weaker for particular seasonal periods.
} 
database to compute a Herfindahl-Hirschman Index (HHI) for the share of land allocated across 16 major crops that account for over $70 \%$ of cultivated land in India. ${ }^{5}$ I compute the index at the district level and report the mean across districts, which increased from 0.41 to 0.43 between 1993 and 2009. ${ }^{6}$ Figure 4 uses the same data to document that the share of land allocated to rice and wheat rose slightly over this period while the share of land allocated to all major grains fell slightly.

Increased agricultural specialization across districts may not be consistent with efficiency increasing and market-oriented land re-allocation. FAO/GAEZ data on agro-ecological conditions has been widely used to assess the potential scope for efficiency gains from land re-allocation across crops. These data provide high resolution predicted yields based on climate, soil and terrain conditions for individual crops. I use these data to calculate district-level average potential yields for 13 major crops for which I can also observe annual land usage in the ICRISAT district data. ${ }^{7}$ I then calculate an "ecological comparative advantage index" for each district $d$ as $\sum_{c} \frac{\text { Yiel } d_{c d}}{\text { Yield }_{c}}$ landshare $_{c d}$ where the district potential yield relative to the all-India average potential yield $\left(Y i \bar{e} l d_{c}\right)$ is weighted by the district's land share for each crop. Changes in this index reflect the degree to which the correlation between land allocations and relative productivity at the district-level are increasing or decreasing. As the level of this index also captures absolute advantage (e.g. some districts have higher potential yields for all crops) one can divide it by a counter-factual index in which land is allocated based on the all-India district average shares $\left(\sum_{c} \frac{\text { Yield }_{c d}}{\text { Yield }_{c}}\right.$ landshare $)$ for cross-sectional comparison. Figure 4 shows that changes in land shares over this period lowered ecological comparative for the average district between 1993 to 2004 but raised it between 2004 to 2009 to levels above 1999.

Further insight into heterogeneity across districts in land allocations can be seen in the bottom panel of Figure 4. Here I plot the kernel density of the district share of land allocated to grains for 1993 and 2009. The density displays a bimodal distribution in 1993, but by 2009 mass shifts to the top and especially the bottom tail.

\footnotetext{
${ }^{5}$ These are rice, wheat, sorghum (jowar), pearl millet, maize, finger millet (ragi), barley, chick pea, pigeon pea (arhar/tur), ground nut, sugar, cotton, sesamum, rapeseed/mustard seed, castor seed and linseed.

${ }^{6}$ In the ARIS/REDS data household-level land share HHI also show an increase in specialization with a rise from 0.75 to 0.78 between 1999 and 2006.

${ }^{7}$ I use the intermediate input usage model, and to be consistent with the ICRISAT VDSA I use a 1961 district boundary shapefile for the calculation. The major crops are the same as the 16 crops used for Herfindahl indexes minus castor seed, linseed and sesamum.
} 
Much of the increase in density of districts with very low shares of land allocated to grains comes from districts that initially had modest shares in the $30 \%-50 \%$ range, which is consistent with increased specialization for some districts away from grains towards other types of crops that tend to be more market-oriented and have lower own-consumption value.

To recap, the evidence presented in this section highlights that there has been a modest trend towards agricultural specialization in India across districts, some of which is related to re-allocation of land used for rice/wheat and staple production. These re-allocations can potentially affect farmer incomes and the exploitation of ecological comparative advantage and are plausibly related to consumption needs, particularly for small farmers.

\subsection{Marketization costs}

Just as consumption and production decisions are linked at the aggregate market level by "trade costs" between markets, consumption and production decisions at the household level can be linked by "marketization costs" between the household and the local markets where they sell their output and purchase goods. For rural households that decide whether to produce or buy their food, factors such as travel and search costs or uncertainty about selling and buying prices may favor producing goods for own consumption over acquiring goods through the market. ${ }^{8}$ Faced with these costs, households may choose to produce crops that do not maximize their market (cash) income but that satisfy consumption needs when the opportunity cost of satisfying them through market exchange is high.

A lower bound on these marketization costs that is more readily observable is the gap between the price at which a household can sell a crop to the market and the price at which it can purchase the same crop from the market. This gap includes both distribution costs and markups. The NSS consumption data record the unit value (expenditure divided by quantity) for major crops purchased by households. This can be compared to two sources of data on selling prices - the ex-farm gate

\footnotetext{
${ }^{8}$ For evidence on transaction costs for purchasing goods in India, see Li (2021). For evidence on transaction costs for selling goods, see Fafchamps and Hill (2005), Fafchamps et al. (2005) and also Gollin and Rogerson (2010). For evidence of the link between price volatility and crop choice, see Fafchamps (1992) and Kurosaki and Fafchamps (2002). For evidence on the welfare cost of price uncertainty for buying staples in India, see Gardenne (2020) and Gardenne et al. (2021). For the importance of information frictions and search costs, see Casaburi et al. (2013) and Allen (2014).
} 
price recorded by the NSS (used to impute the consumption value of home produced crops) and the harvest price data recorded by ICRISAT from agricultural wholesale markets (mandis). For the NSS data I use median unit values for rural areas of districts to compute these gaps. The measured gaps are undoubtedly contaminated by measurement/sampling error and heterogeneous quality, but illustrate the potential magnitude of marketization costs. Table 1 reports the ratio of the NSS market purchase price over either the NSS farm-gate price or ICRISAT harvest/mandi price for 11 of the most important foods. I report the average ratio for all districts where I observe both the buying and selling prices. ICRISAT harvest prices are lower than NSS farm-gate prices resulting in larger ratios - on average 1.39 and 1.14 in 1993, rising to 1.49 and 1.19 respectively in $2009 .{ }^{9}$ The fact that these gaps have actually risen is somewhat surprising and suggests that to the extent that average marketization costs have fallen over the period it must be due to the less observable components of marketization costs rather than the observable price wedges. Rice is an important exception as the buying/selling price gap fell using either selling price measure.

The magnitude of these gaps can be contrasted with price dispersion across districts. Table 1 also reports the ratio of the 75th to 25th percentile purchase prices or selling (ICRISAT harvest) prices across districts. The market purchase price gaps are larger than the harvest price gaps, which likely reflects the fact that harvest prices are only observed for producing districts, which may have more similar agricultural endowments/crop suitability and may be closer geographically. Market price gaps are observed for any district with positive consumption. The across district price gaps have a similar magnitude to the within-district buying/selling price ratio, which suggests that within-district marketization costs could be as important as across district/across market trade costs in terms of their effects on land allocation, particularly for small farmers. Also note that the price dispersion across districts has not necessarily fallen over this period - while the 75th-25th harvest price ratio fell from 1.28 to 1.21 for the average listed food, the equivalent market price ratio rose from 1.50 to 1.54. This is consistent with the observation that there are continued high barriers to agricultural trade in India despite some liberalization and improvements in highways and transportation infrastructure during this period. ${ }^{10}$

\footnotetext{
${ }^{9}$ The reason for this is not clear but it may partly reflect the fact that the ICRISAT prices are taken at a time in the year (harvest) when selling prices are lowest, while the NSS data are collected year round as long as households are consuming their own output.

${ }^{10}$ See Atkin (2013) for a discussion of internal trade barriers and reforms, Leemput (2021) for evi-
} 
Transport costs and access to credit are two of the more important factors that could influence marketization costs for rural households. Roads affect the ability of farmers to access markets directly and can also lower the distribution costs of intermediaries along the supply-chain from farm to market. To measure the roads that matter for local market access, I use district road length per square kilometer from ICRISAT. Access to credit can help farmers mitigate the risk that comes with marketoriented production and/or may facilitate the acquisition of necessary inputs. I measure farmer access to credit using Fulford (2013)'s data on rural bank branches per capita at the district level.

Figure 5 looks at the correlation between these district-level factors capturing marketization costs and three outcomes that capture different aspects of marketization the home share of food for farmers, the fraction of rural households classified as farmers, and the ecological comparative advantage index introduced earlier. The figure shows that there is significant dispersion in road density, rural bank access, and marketization outcomes across Indian districts in 1993. Districts with higher road density appear more "marketized" in all three measures, while districts with higher rural bank access are more "marketized" in terms of the home share of food for farmers and land allocations. These cross-sectional correlations suggest that improvements in rural road density and rural bank access may have contributed to the evolving agricultural specialization patterns earlier. They also suggest that some districts with high marketization costs - proxied by a high home share of food for farmers, poor road access, or poor access to credit - may feature a stronger link between shocks to consumption, of the kind generated by PDS expansion, and changes in agricultural production and specialization.

\subsection{Public Distribution System}

Until 1992 the PDS was a universal program designed to provide all households with an entitlement to a fixed quantity of rice and/or wheat (typically $10 \mathrm{KG} / \mathrm{month}$ ) at fixed prices to supplement market provision of these goods and ensure some level of food access and price stability. The central government procured grains from farmers using a minimum support price and set "central issue prices" not exceeding these

dence on the size of internal trade barriers in India, and Ghosh (2011), Mallory and Baylis (2012), and Chatterjee (2020) for evidence of low spatial integration of prices across Indian agricultural markets during this period. 
support prices, absorbing the costs of procurement, storage, and distribution to the states. States were charged with distributing goods to households through a network of state-managed fair price/ration shops or licensed agents (over half a million by 2011) and oversaw the distribution of ration cards. The combination of prices typically below market and widespread access through a large network of shops ensured that there was significant usage and value to recipients from the program (Figure 2). Even under this universal regime there was substantial variation in the quality and availability of PDS rice and wheat across and within states, with small variation allowed in state prices to cover costs and substantial variation in the subsidy value due to differences in market prices.

Beginning in 1992 the system was "revamped" to better target specific remote and poor areas where PDS usage was low and increase their entitlement up to 20KG / month. In 1997 the system began transitioning to a "targeted" system with the goal of directing more of the subsidy to below poverty line (BPL) households. BPL allotments to states were based on estimated poverty rates in 1993, while allotments for above poverty line (APL) households were based on historic offtake. Initially APL households received their original entitlement and were charged prices set to cover $100 \%$ of the central government's "economic cost" (related to support prices and operational costs) while BPL households were charged 50\% of "economic cost." However BPL prices were fixed in nominal terms in 2000 and APL prices were fixed in 2002, leading to an increase in the subsidy value for all households as "economic cost" rose. In 2000 the Antyodaya Anna Yojana (AAY) program was introduced to target the poorest BPL households with a larger subsidy and a larger $(25 \mathrm{KG} /$ month) entitlement, while BPL allotments to states increased to $20 \mathrm{KG}$ /month per household. In 2002 the entitlements for AAY, BPL and APL households increased to $35 \mathrm{KG} /$ month (Balani (2013), Planning Commission (2002), Government of India Department of Food and Public Distribution (2021)). The number of BPL households and AAY households in each state for the purpose of state-level allotments was also revised upwards over time based on population growth and expansion of the AAY program. It is important to note that while these entitlements are reasonably large, for most households that use the PDS these quantities are infra-marginal. Over three quarters of households that consume PDS rice also consume rice from another source during the 1993-2009 period and the share rose over this period despite the increase in PDS quantities.

An important feature of the transition to the Targeted PDS system is that it varied 
substantially across states. State allotments varied both due to differences in estimated poverty rates and historical offtake of APL households, and the "offtake" of many states was below their allotment (Appendix figure A2). Conditional on state offtake, PDS expansion varied both due to pre-existing differences in PDS systems across states and because states managed the allocation of ration cards and distribution to shops, with freedom to charge higher prices to cover their additional costs (since 2001) or to lower prices and/or increase entitlements using their own funds. ${ }^{11}$ An extreme example is Tamil Nadu where the PDS remained a universal entitlement with only a single type of ration card, resulting in an entitlements that were priced lower than other states but that also featured a smaller, household-size dependent quantity. In addition to statutory differences across states, there are large differences between offtake and NSS measured consumption (Appendix Figure A3) due to "ghost" ration cards and leakage into the open market during this period. ${ }^{12}$ Unavailability of monthly entitlements to card-holders and differences in market prices also generated differences in the quantity and implicit value of PDS entitlements across states.

Figure 6 provides a scatter plot of state-level variation in 1993 and 2009 in the fraction of households consuming PDS grains, the quantity of PDS grains consumed per capita, the quantity of PDS grains per capita for recipient households, and the implicit subsidy value (quantity multiplied by the gap between market and PDS prices) for recipient households. ${ }^{13}$ Figure 6 shows that there was large variation across states in PDS usage, quantities and implicit value in 1993 despite the "universal" nature of the entitlement. While there is some correlation across the different measures of PDS intensity, there is a lot of variation in terms of quantity vs. subsidy value vs. fraction of the population served. States with higher initial PDS intensity tended to have larger increases in PDS intensity between 1993 and 2009 and most states saw increases along all of these margins. However, some of the states with lowest initial PDS intensity had some of the largest increases (e.g. Orissa and Madhya Pradesh)

\footnotetext{
${ }^{11}$ See Balani (2013) and Commission (2005) for a discussion of targeting issues. In 2002 the central government carried out a BPL census to improve classification. States were supposed to follow this classification for the central PDS entitlements starting in 2006, but in 2009 there was still evidence of substantial errors of inclusion and exclusion.

${ }^{12}$ Leakage was estimated to range from $36 \%$ to $50 \%$ in the 2000 s with substantial variation across states (Khera (2011b), Balani (2013)).

${ }^{13}$ See Commission (2005) for a description of the statutory variation in PDS entitlements across some states.
} 
and some with the highest initial PDS intensity even had decreases along some margins (e.g. Kerala).

Before moving on, it is worth noting two other important policy developments during this period. First, procurement of rice and wheat for PDS is heavily concentrated in a few states, particularly Punjab and Haryana (Murthy and Ramanayya (2007)). Minimum support prices rose relative to market prices between 1993 and 2009 and the support prices became particularly binding in these areas and began to bite in others, increasing the magnitude of government procurement over time. Part of the impetus for keeping central issue prices frozen and increasing PDS allotments was that procurement exceeded offtake in many years, resulting in large storage and spoilage costs for the government. Any overall assessment of the PDS and its effects on agricultural production needs to consider the implications of the procurement necessary for its functioning, which is beyond the scope of the analysis here. However, Appendix Figure A4 shows that the procurement is highly concentrated in a few states and has no discernible relationship with offtake; where applicable my analysis will control for state level procurement, the most disaggregated measure of procurement available, but results are similar when excluding the most impacted states.

Second, another major welfare scheme targeting the rural poor was introduced during this period - the National Rural Employment Guarantee Act (NREGA), which was phased in between 2006 and 2008 and offered guaranteed work at a minimum wage for 100 days to any household. This program was more likely to be used by agricultural laborers than farmers as they face a longer "lean" season, but it benefited many marginal farmers and has been shown to impact agricultural production patterns (Raghunathan (2016)). By 2009 NREGA was universal across districts and households although it was more likely to benefit households with BPL or AAY cards. The scale of the program was substantially smaller than PDS, with less than 18 million households estimated to have used the program by 2010 (under 7\% of sample households in 2009). In my district-level analysis I control for the share of households that use NREGA in 2009 in case this is correlated with PDS expansion at the district-level between 2004 and 2009. 


\section{Model}

This section introduces a simple Ricardian model that motivates the empirical analysis of the effects of PDS expansion on agricultural production. The model abstracts from factor input markets to focus on the interaction between output market frictions, household consumption and two key production decisions - whether to farm, and if so which crops to farm.

\subsection{Basic setup}

Consumers have Stone-Geary utility functions defined over a food staple $s$ and a market good $m$. Utility is defined as $U=\left(q_{s}\right)^{\alpha}\left(q_{m}+\gamma\right)^{1-\alpha}$ where $\gamma>0$ implies that the market good is a luxury and the staple is a necessity. The staple good has price $p_{s}$ and the price of the market good is normalized to one $\left(p_{m}=1\right)$. Households with income $Y$ face standard demand functions given by $q_{m}=(1-\alpha) Y-\gamma \alpha$ and $q_{s}=\frac{\alpha Y}{p_{s}}+\frac{\gamma \alpha}{p_{s}}$.

Household $i$ has productivity in three sectors: off-farm $\left(A_{i, o}\right)$, market farm $\left(A_{i, m f}\right)$, and staple farm $\left(A_{i, s f}\right)$. Households have an endowment of a single input $L$ that they can allocate freely across the three sectors. The input endowment can be interpreted as labor, land, or a combination of both but for simplicity I abstract from factor input markets since my focus is on how output market frictions affect share of inputs allocated to each sector. Assuming linear production technology, households choose to maximize their income by devoting all of their time to the sector that generates the highest income, with $Y_{i}=\max \left\{A_{i, o}, A_{i, m f}, p_{s} A_{i, s f}\right\} L_{i}$. The home-produced share of consumption is zero for market farmers and off-farm households, while for staple farmers it is bounded from above by the food budget share but is otherwise indeterminate since staple farmers are indifferent between selling all of their output or only part of it.

\subsection{Marketization costs}

Suppose there is a "marketization" wedge $(\tau)$ between the price at which farmers can sell their crop $\left(p_{s}\right)$ and the cost of purchasing it from the market $\left(p_{s}(1+\tau)\right)$. The cost of purchasing from the market could be interpreted narrowly as the retail/market price (with wedges then corresponding to the ratio of market to farm-gate or harvest 
prices in Table 1) or more broadly as all welfare relevant factors that could make home production of a unit of staples more attractive than purchasing from the market, e.g. including travel/search costs and the (consumption-equivalent) cost of uncertainty in prices and availability.

Given this additional assumption, household $i$ will sort into one of five production patterns depending on relative productivity, the staple-selling price and the marketization wedge:

1. If $A_{i, o}>\max \left[A_{i, m f}, A_{i, s f} p_{s}(1+\tau)\right]$, the household is a specialized non-farmer. Production for home consumption is zero. Utility is given by $V_{i}=\alpha^{\alpha}(1-$ $\alpha)^{1-\alpha}\left(\frac{1}{p_{s}(1+\tau)}\right)^{\alpha}\left[A_{i, o} L_{i}+\gamma\right]$.

2. If $A_{i, m f}>\max \left[A^{i, o}, A^{i, s f} p_{s}(1+\tau)\right]$, the household is a specialized market farmer. Production for home consumption is zero. Utility is given by $V^{i}=\alpha^{\alpha}(1-$ $\alpha)^{1-\alpha}\left(\frac{1}{p_{s}(1+\tau)}\right)^{\alpha}\left[A_{i, m f} L_{i}+\gamma\right]$.

3. If $A_{i, s f} p_{s}>\max \left[A_{i, o}, A_{i, m f}\right]$, the household is a specialized staple farmer. All consumption of staples is sourced out of home production and the home produced share of consumption is strictly decreasing in staple output. Utility is given by $V_{i}=\alpha^{\alpha}(1-\alpha)^{1-\alpha}\left(\frac{1}{p_{s}}\right)^{\alpha}\left[A_{i, s f} L_{i} p_{s}+\gamma\right]$.

4. If $A^{i, o}>A_{i, m f}$ and $A_{i, s f} p_{s}(1+\tau)>A_{i, o}>A_{i, s f} p_{s}$, the household is a mixed staple farmer/non-farmer. All consumption of staples is sourced out of home production and the home produced share of consumption is strictly decreasing in nonfarm productivity. Utility is given by $V_{i}=\left(\lambda_{i, s f} A_{i, s f} L_{i}\right)^{\alpha}\left(\left[1-\lambda_{s f}\right] A_{i, o} L_{i}+\gamma\right)^{1-\alpha}$ where $\lambda_{i, s f}=\alpha\left[1+\frac{\gamma}{A_{i, o} L_{i}}\right]$ is the share of inputs allocated to staple farming.

5. If $A_{i, m f}>A_{i, o}$ and $A_{i, s f} p_{s}(1+\tau)>A_{i, m f}>A_{i, s f} p_{s}$, the household is a mixed staple farmer/market farmer. All consumption of staples is sourced out of home production and the home produced share of consumption is strictly decreasing in market farming productivity. Utility is given by $V_{i}=\left(\lambda_{s f} A_{s f}^{i} L_{i}\right)^{\alpha}\left(\left[1-\lambda_{i, s f}\right] A_{i, m f} L_{i}+\gamma\right)^{1-\alpha}$ where $\lambda_{i, s f}=\alpha\left[1+\frac{\gamma}{A_{i, m f} L_{i}}\right]$.

Marketization costs lead some households that would otherwise have been specialized in off-farm production (including as agricultural laborers) to pursue limited staple farming to satisfy their own consumption needs. Empirically, this could be reflected in a higher share of the population classified as farmers if some non-farmers 
now spend a majority of their (imputed) income on home-produced staples. On the intensive margin, it could also show up as an increase in labor allocated to farming relative to other activities for any type of household.

Marketization costs can also lead to a higher home produced share of consumption. Under linear production technologies, switching from specialized market farming or specialized non-farming to mixed staple farming entails a large and discontinuous increase in the home produced share of consumption. ${ }^{14}$ The home produced share of consumption also depends on a household's productivity and endowment, so at an aggregate level it is likely to capture both the level of marketization costs and the stronger implications of marketization costs for poor households.

Finally, marketization costs can lead to input allocations that deviate from comparative advantage in terms of exogenous land-based productivity. For mixed farmers that produce the market crop because they have a higher market return but also produce staples for own-consumption, those with more land and/or higher productivity devote a decreasing share of their inputs to staples. As observed in Figure 3, the share of land allocated to crops with a higher-market value (but lower home consumption value) rises with land cultivated within-village, which is consistent with the model under marketization costs. Higher marketization costs could increase the share of land devoted to staples in locations that might have a (market-based) comparative advantage in other crops.

Note that all of these features of the model are consistent with the data in Figure 5 to the extent that roads or rural credit availability are proxies for low marketization costs - districts with lower marketization costs have a smaller share of the rural population engaged in farming, a lower share of consumption out of home production for farmers, and land allocations that are more consistent with exogenous comparative advantage.

\subsection{PDS transfers in partial equilibrium}

A PDS entitlement allows households to purchase a quantity of the staple good $\left(q_{s, P D S}\right)$ at a price below the market price $\left(p_{P D S}\right)$. For most households, the PDS entitlement

\footnotetext{
${ }^{14}$ With heterogeneous productivity across land plots or labor units, or another source of diminishing returns (e.g. along the lines of a specific factors model), the increase would be smoother and more continuous. At the aggregate level a model with linear production and a continuous distribution of household productivity feature would typically feature similar smooth adjustments with respect to changes in marketization costs.
} 
is infra-marginal (below the desired consumption quantity) and I maintain this assumption throughout the rest of the analysis for simplicity.

With no marketization costs, infra-marginal subsidized entitlements like the PDS have an income effect equivalent to a cash transfer valued at the difference between the market and PDS price multiplied by the quantity of the PDS transfer. The demand function for staples in this case is given by $q_{s, m k t}+q_{s, P D S}=\frac{\alpha}{p_{s}}\left[Y_{i}+\gamma\right]+\alpha q_{s, P D S}\left[1-\frac{p_{P D S}}{p_{s}}\right]$. Since staples are still a normal good in the model, we would expect to observe an increase in staple consumption that is positive (with respect to the PDS quantity $q_{s, P D S}$ ) driven entirely by the income effect $\left(p_{P D S}<p_{s}\right)$. Purchases of staples from the market decrease but by less than the PDS quantity. Because consumption and production are separable in this case, there are no effects on production. However, households specializing in staple farming, who are indifferent to sourcing their staples from the market or out of their own production, may lower their consumption of staples from home production.

With marketization costs, the effects of a PDS entitlement are more subtle. The PDS prices before the transition to the targeted PDS were likely below the cost of purchasing staples on the market inclusive of marketization costs $\left(p_{s}(1+\tau)\right)$, although they may have been higher than the staple selling price $\left(p_{s}\right)$. The transition to targeted PDS resulted in prices that were even lower than the staple selling price $\left(p_{s}\right)$ as well as expansion of the entitlement quantity.

Even with marketization costs, fully-specialized households do not change their production in response to the PDS expansion. Specialized market farmers and specialized non-farmers have demand functions for staples given by: $q_{s, m k t}+q_{s, P D S}=$ $\frac{\alpha}{p_{s}}\left[Y_{i}+\gamma\right]+\alpha q_{s, P D S}\left[1-\frac{p_{P D S}}{p_{s}(1+\tau)}\right]$ and will increase staple consumption to the extent that there are income effects from the transfer (because $p_{P D S}<p_{s}(1+\tau)$ ). Specialized staple-farmers will substitute PDS staples for home-produced staples in their consumption as long as $p_{P D S}<p_{s}$. The decrease in consumption of home-produced staples is not one-for-one, since staples are still a normal good and there are income effects from the transfer, but the share of consumption out of home production will necessarily fall.

For households that engage in market-farming or off-farm work but produce staples to satisfy their consumption needs, there is a similar reduction in consumption of home-produced staples as long as the PDS price is below $A_{i, s f} p_{s}(1+\tau) / A_{i, m f}$ or $A_{i, s f} p_{s}(1+\tau) / A_{i, o}$. However there are also important production effects, as these house- 
holds decrease their production of staples and re-allocate inputs towards production of marketed farm or non-farm output. The share of inputs devoted to staple produc-

tion in this case (for the mixed staple-farmer/non-farmer) is $\lambda_{i, s f}=\alpha\left[1+\frac{\gamma}{A_{i, o} L_{i}}\right]-$ $\frac{q_{s, P D S}}{L_{i}}\left[\frac{\alpha}{A_{i, o}}+\frac{(1-\alpha) p_{P D S}}{A_{i, s f}}\right]$. This implies that $\frac{\partial \lambda}{\partial q_{P D S}}=\frac{1}{L_{i}}\left(\frac{\alpha}{A_{i, o}}+\frac{(1-\alpha) p_{P D S}}{A_{i, s f}}\right)$ and that $\lambda_{i, s f}$ is decreasing in the quantity of the PDS transfer $q_{P D S}$. For these households, a reallocation of inputs away from staple-farming increases market income.

Obseve that increases in the per unit subsidy value of the PDS entitlement can raise $\lambda$ in this context. A decline in $p_{P D S}$ generates an income effect that increases the demand for staples; holding $q_{P D S}$ constant, this greater demand for staples is met by increased staple farming for these mixed households. This is similar to the effect of a cash transfer, which increases staple and market good consumption and therefore also increases staple production for households engaged in staple farming for own consumption.

The model provides guidance on the potentially heterogeneous impact of a given PDS entitlement across households that have non-zero production effects. The expression for $\frac{\partial \lambda_{s f}}{\partial q_{P D S}}$ indicates that households with higher $L$ see a smaller re-allocation of inputs (in share terms) than households with lower $L$ all else equal. A similar effect holds for households with higher productivity. These households require a smaller re-allocation of inputs away from staple production to keep staple consumption at the optimal level in response to an increase in $q_{P D S}$. Note that in either case (high land or high productivity) these households have lower shares of consumption out of own production. Households that face higher marketization costs also have a higher share of consumption out of own production and are more likely to be in a regime where there are production-side responses to PDS entitlements. Thus households with a higher home-produced share of consumption (or equivalently a higher share of agricultural output consumed) will have larger production side responses to expansion of PDS entitlements whether due to poverty (low inputs/low productivity) or high marketization costs.

\subsection{PDS transfers in general equilibrium}

In general equilibrium, where the level of PDS entitlements can affect prices, the implications of PDS entitlements are more ambiguous. Production decisions of households that do not receive PDS entitlements and transfers to households that do not 
engage in staple production can affect staple production through equilibrium prices. PDS entitlements increase the supply of staples more than the demand, crowding out purchases from the market and putting downward pressure on staple prices. This effect may be mitigated by three factors. First, some locations in India may be relatively small and integrated such that they behave like small open economies - the local level of PDS entitlements then exerts a minimal effect on prices. Second, the Indian government implements a minimum support price for rice and wheat that in recent years has been binding in many parts of India; this puts a floor on any potential effects of PDS entitlements on the prices that farmers receive for staple crops. Third, since the PDS entitlements have an income effect and rice and wheat are normal goods (with higher income elasticities than some other staple grains), the effect of PDS expansion on local prices may be attenuated by the rise in rice/wheat demand due to income effects.

If PDS entitlements lower local staple prices, this would amplify the partial equilibrium (direct) effects of PDS receipt outlined previously. A decrease in staple prices could induce switching away from staple farming for specialized staple farmers for whom $p_{s} A_{i, s f}>A_{i, m f}>p_{s}^{\prime} A_{i, s f}$ or $p_{s} A_{i, s f}>A_{i, o}>p_{s}^{\prime} A_{i, s f}$. This channel could affect PDS non-recipients and recipients alike and does not require marketization costs as it affects the incentives for market-oriented staple production. Even if the selling price $\left(p_{s}\right)$ is unaffected (e.g. due to government intervention), a decrease in market purchase prices for staples $\left(p_{s}(1+\tau)\right)$ could also disincentivize staple production for home consumption. This channel would affect PDS recipients and non-recipients alike, but operates through the marketization cost channel by decreasing production intended for own consumption rather than affecting the incentives for marketoriented staple production. Both of these channels would decrease staple output and induce exit from farming and lower consumption from home production.

The implications of openness are interesting to consider in this context. If openness leads to smaller price changes, this might be expected to lead to lower GE effects on staple output for locations that are more open. On the other hand, if districts that are more open have more households that are closer to the margin of switching from staple farming to market farming (or switching out of staple farming for own consumption), a given price change might induce a larger decline in staple output. Ultimately, the additional general equilibrium effects of PDS expansion on staple output and inputs allocated to staple production is an empirical question that depends 
on both the magnitude of the price response and the effects of a given price change on household comparative advantage and the attractiveness of production for home consumption.

\subsection{Summary of PDS effects on production}

In partial equilibrium, PDS entitlements have no partial equilibrium effect on production without marketization costs. With marketization costs, they lower the share of consumption out of home production for households that produce staples. For households that produce staples only to satisfy their own consumption needs, there is a negative effect on the share of inputs allocated to staple-farming driven by the quantity effect of PDS. A decrease in PDS prices (holding constant quantity) acts like a cash transfer and increases staple production for these households. Any decrease in staple production for these households increases market income by allocating resources more efficiently from a market perspective. This includes both re-allocation to more market oriented crops and exit from from farming. The partial equilibrium effects on production are larger for households with higher home shares of consumption because they have lower inputs and productivity or face higher marketization costs.

In general equilibrium, higher PDS entitlements may lower staple prices. This can lower staple production for two additional reasons that affect PDS recipients and non-recipients alike - a decrease in the staple selling price induces switching of market-oriented production away from staples, while a decrease in the staple buying price induces re-allocation of inputs away from staples intended for home consumption. Because both the partial equilibrium and additional general equilibrium effects are larger with marketization costs, we would expect larger production effects for locations with higher marketization costs and agricultural production that is more oriented towards own consumption.

\section{Estimating the effects of PDS receipt on agricultural production and specialization}

I now consider the empirical evidence for production-side effects of the PDS expansion between 1993 and 2009 and assess whether these effects are mediated by proxies 
for marketization costs or other plausible mechanisms. I first explore partial equilibrium effects using NSS data for consumption outcomes and ARIS/REDS data for production outcomes. These data allow me to compare households in the same village that receive different levels of PDS entitlements. I then turn to ICRISAT data to look at district-level general equilibrium effects on prices, output, and production specialization due to variation in per capita PDS entitlements within districts over time.

\subsection{Household consumption effects: evidence from the NSS} (1993-2009)

India's National Sample Survey provides two sources of variation in PDS entitlements at the household level - whether a household holds a BPL card that entitles it to different prices and/or quantities for food-grains (for the 2004-2005 round only) and the quantity and cost of PDS grains consumed by the household (from 1993 onwards). Households that do not possess BPL cards can still purchase PDS grains, but the price/quality differential relative to the market is low enough that most of these households do not use their entitlement (see Figure 6). Thus BPL cards are highly predictive of the quantity of PDS grains consumed since it is the discounts provided by these cards that make PDS attractive during this period. Note that poor households may not have BPL cards and rich households may possess BPL cards and there is evidence of significant errors of inclusion and exclusion during this period (Balani (2013),Commission (2005)). ${ }^{15}$

Table 2 Panel A reports results from a regression of various household consumption outcomes on an indicator for BPL card ownership. The outcomes include the quantity of rice/wheat consumed (in kilograms per person per month), the quantity purchased from the market, the quantity purchased out of home production, and the share of total food consumption sourced from home production. I include village dummies so BPL card holding households are being compared to other households in the same village that otherwise face the same menu of prices for buying and selling rice and wheat. Since a naive comparison of BPL to non-BPL households will

\footnotetext{
${ }^{15}$ In the 2004-2005 NSS data where I can examine this directly, 6\% of rural households without BPL cards consume PDS grains (with mean quantity $0.36 \mathrm{KG} / \mathrm{pp} / \mathrm{month}$ and implicit value 0.571993 rupees/pp/month) and $62 \%$ of rural households with BPL cards consume PDS grains (with mean quantity 3.30KG/pp/month and implicit value 8.471993 rupees/pp/month). I exclude Tamil Nadu for these calculations as PDS entitlements are not related to BPL cards.
} 
confound the effect of the PDS entitlement with differences in income, wealth, and demographics that are likely to be predictive of staple consumption, I also include household controls: dummies for household size, household head education and gender, religion, scheduled caste and scheduled tribe status, as well as demographic ratios (fraction of adult and senior males and females), and a quadratic in log real per capita expenditure (1993 rupees). Given these controls, variation in BPL card ownership can be interpreted as being driven by some combination of misallocation of cards and the details of the formula that dictates BPL allocation (which depends on asset ownership and thresholds for income and land in the 1990s and early 2000s and was revised in later years to account for additional factors). Controlling for expenditure accounts for the most obvious confound that would be correlated with both BPL status and staple consumption.

Column 1 of Table 2 Panel A shows that BPL card ownership increases rice and wheat consumption substantially by 0.74 kilograms per person per month. This is somewhat low given the typical household size (about 5 during this period) and the theoretical size of the PDS entitlement offered by the central government, but reflects (a) the reality that some BPL card-holding households either cannot or choose not to purchase their full PDS allocation every month, (b)statutory state entitlements are often well-below the central allocation during this period, (c) some non-BPL households use the PDS and in some states the BPL discount is smaller or zoer, and especially (d) the fact that rice/wheat have an income elasticity well below one. Columns 2 and 3 show that there is significant crowding out of rice/wheat consumption sourced from the market and out of home production. Column 4 shows that the share of consumption out of home production is a full four percentage points lower for households with BPL cards.

In column 5, instead of quantities I regress a dummy for whether a household is a farmer on the same set of variables. Because land holdings are part of the criteria for BPL status and are highly correlated with the propensity to farm, interpretation is less straightforward, but the large negative correlation is at least consistent with the potential for BPL card ownership to decrease the household allocation of inputs to self-employment in agriculture. In columns 6 through 8, I restrict the sample to farmers only and also control for a quadratic in land possessed. We observe similar decreases in consumption of home produced rice/wheat and the share of consumption out of home production for households classified as farmers. Column 8 interacts 
the BPL card indicator with a dummy for whether the farming household is "poor" which I define as having per capita expenditure below the median for farmers and finds larger effects for these households.

In Panel B of Table 2 I use measures of PDS consumption instead of BPL card ownership. I include the quantity of PDS grains purchased per person per month in kilograms (directly comparable to the consumption outcomes) but also a measure of the value of the PDS transfer per capita to capture income effects. The value is measured as the difference between what the household paid for its PDS consumption and what that quantity would cost at village median (or state median if missing) market prices. To assist with interpretation of magnitudes, recall that between 1993 and 2009 the PDS quantity variable (KG/pp/month) increased by about 1 for all households and by about 1.5 for households that used the PDS (Figure 2), while the value of PDS transfers increased by about 8 (1993 rupees/pp/month) for all households and 16 for households that used the PDS. As I use the full 1993-2009 sample for this analysis, I also include a dummy for PDS usage interacted with state-round dummies. Unlike the BPL card regressions, identifying variation comes from differences in PDS quantity and value for PDS receiving households rather than comparisons of PDS to non-PDS households. Other national or state level programs during this period that might differentially affect PDS and non-PDS consuming households, as well as differential selection into PDS consumption across states and over time, are captured by these controls.

The results in Panel B of Table 2 are qualitatively consistent with those of Panel A using this alternative source of variation. PDS quantities increase consumption quantities but by less than one for one, due to crowding out of consumption from market and home sources. The model implies that conditional on income effects (captured by the PDS value variable) there should not be any effects on total consumption from an infra-marginal transfer. However, the value of the PDS transfer may not be fully captured by my measure to the extent that market purchases involve greater risk or transaction costs. It is also the case that the transfer is not infra-marginal for some households (about 25\%) and there could be resale frictions. An alternative interpretation is that households exhibit some behavioral effects consistent with paternalism.

The value of PDS transfers (holding constant quantity) has the expected positive income effect on consumption. While purchases from the market are not strongly affected, there is a significant increase in consumption from home production. This 
is exactly the prediction of the model with marketization costs. Holding constant the quantity of the PDS transfer, increasing the value of the transfer (by lowering the PDS price relative to the market price) makes households want to consume more rice/what, and the most efficient way to do this for some households is to produce it themselves due to high marketization costs.

\subsection{Household production effects: evidence from ARIS/REDS (1999-2006)}

The ARIS/REDS data have the advantage of collecting detailed household production data for rural households and also feature a household panel, but the PDS data are more limited. As mentioned earlier, the 1999 survey did not collect any information on PDS usage by households, but the 2006 survey collected information on the value of PDS entitlements (in rupees) during the current and previous two village governments. As a first step, I impute the value of PDS entitlements in 1999 for the panel households under the assumption that this was two elections ago. ${ }^{16}$ To assist in interpreting magnitudes, the PDS variable (measured in 1000s of 2006 rupees) rises from about 0.9 to 1.3 for the full sample between 1999 and 2006. The measure is likely to be noisy due to both the nature of the recall and the timing imputation, but it allows for the use of PDS variation within households over time. Note that most of the expansion of the value of PDS to households during this period occurred along the quantity margin rather than the subsidy value per unit (2).

The first set of outcomes I consider are the four land allocation outcomes highlighted in Figure 3 - the share of land allocated to rice and wheat, the share of land allocated to all major grains, the consumption crop index (which weights aggregate shares of each crop's output consumed by household crop land shares) and the market value crop index (which weights village average value of output per hectare of each crop by household crop land shares). I also look at net agricultural income (gross value of crops produced minus the cost of inputs purchased from the market including seeds, fertilizers, pesticides, hired machinery and irrigation) and net income (which adds employment income and net non-agricultural enterprise income),

\footnotetext{
${ }^{16} \mathrm{~A}$ village government or Gram Panchayat is elected every 5-years in India so this seems like a reasonable assumption. The value of PDS entitlements from two periods ago then reflects a combination of pre "Targeted PDS" entitlements and expansion during the earliest years but predates the major quantity increases beginning in 2000.
} 
which provide further insight into whether input re-allocations are efficient from a market perspective. I also examine total days of labor on the farm by household and non-household members and the cost of farm inputs purchased from the market. ${ }^{17}$

I restrict the sample to households that consume some of their own agricultural output in 1999, which includes farmers but also many households that would not be classified as "self-employed in agriculture" under the NSS definition. I include household fixed effects and village-year dummies that capture any village-level factors that could be correlated with PDS expansion, including general equilibrium effects on prices. I also control for time-varying household size and land owned. To account for any additional government programs that may be correlated with changes in the value of PDS receipts across households I also include the self-reported value of all other major government programs that are recorded in the survey, which includes maternal healthcare and nutrition, mid-deal meal programs, housing and sanitation subsidies, pensions, and employment programs.

Table 3 presents the results. Panel A presents the average effect of changes in the value of PDS entitlements. Consistent with the marketization cost model, PDS expansion lowers land allocated to rice/wheat, grains, and consumption crops. The market value crop allocation index and net agricultural income both increase and labor input on the farm decreases; these effects that are also consistent with the theory but are not statistically significant at conventional levels. However, the PDS measure used here is noisy and may include some increases in the PDS subsidy per unit, which would be expected to attenuate the estimates econometrically and from the perspective of the model.

The model also predicts that the effects of PDS will be heterogeneous across households - those that face low marketization costs or that are richer to begin with (due to more land and/or higher productivity) should be less affected. To explore this heterogeneity, the rest of the table interacts the PDS value with the initial (measured in 1999) share of agricultural output consumed (Panel B), the initial land owned in acres (Panel C), and both interactions (Panel D). In Panel B, the interaction of PDS and share of agricultural output consumed is highly significant and negative for rice/wheat

\footnotetext{
${ }^{17}$ Appendix Table A provides evidence on some additional outcomes that are components of these variables, including rice, wheat, and coarse grains land allocations, employment and non-agricultural enterprise income, individual inputs purchased from the market, family labor, and versions of the consumption and market value crop index using aggregates for households with below or above 4 hectares of land respectively.
} 
area, grain area, and the consumption crop index while the direct effect of PDS is close to zero. The interactions for market value crop index and net agricultural income are positive, which combined with the direct negative effects imply a positive and statistically significant effect on these variables for households at the 90th percentile of initial share of agricultural output consumed (about 70\%). The magnitude of the PDS effect is still small for these households though, with the average increase in PDS value between 1999-2006 leading to a 0.6 percentage point decrease in share of land allocated to rice/wheat or grains and a $1.1 \%$ increase in net agricultural income.

Panel C shows a reverse pattern for the interaction term when using initial land owned as the interaction. As predicted by the theory, larger farmers have smaller production side effects of PDS transfers, with smaller reductions in the share of land allocated to rice/wheat, grains and consumption crops and smaller increases in land allocated to crops with higher market value. Panel D includes both sets of interactions. The two measures are correlated, particularly within a village, so the interactions become noisier, but variation in the initial share of output consumed appears to be more predictive of the magnitude of the output response to PDS for land allocated to crops for home consumption. One interpretation of this is that the initial share of output consumed captures both variation in land but also variation in other sources of productivity and marketization costs across households (including those that vary across villages) and these other factors are more important for land allocations. I focus on this dimension of heterogeneity for the rest of the analysis.

To address the noisiness of the PDS measure I consider an alternative specification that replaces the value of self-reported PDS benefits with an indicator for positive PDS consumption in 2006. PDS "treatment" in this case captures both an intensive margin effect of PDS expansion (due to increases in the quantity and/or subsidy per unit from PDS between 1999 and 2006 for households that already used the PDS in 1999) and an extensive margin effect (for households that did not use the PDS in 1999). The households that do not consume PDS grains in 2006 in the same village serve as the counter-factual.

Table 4 reports the results of this alternative specification for average effects (Panel A) and interactions with initial share of output consumed (Panel B). The effects are qualitatively similar to those in table 3 but some of the effects and interactions are now larger and more precisely estimated. Treated households reduce the share of land allocated to grains by almost 6 percentage points, the consumption crop index 
falls, and total days worked on the farm decreases by 73 days. For the interacted specification, all of the interactions are statistically significant and go in the direction predicted by theory. For households at the 90th percentile initial share of agricultural output consumed, there are statistically significant decreases in land allocated to grains and consumption crops, decreases in days worked on the farm, and increases in the market crop index and the net value of agricultural output. The magnitudes are much larger than in the specification using PDS value, with a 12.6 percentage point reduction in the share of land allocated to grains and a $3.2 \%$ increase in the net value of agricultural output for these households.

In Appendix Table A3 I report a similar specification using only extensive margin changes in PDS usage - I consider a household as treated in 1999 if they report PDS usage two village government elections ago, so identification of PDS expansion effects comes comes only from households that start or stop using the PDS between the two periods. There are 585 panel households that start and 57 that stop consuming PDS grains between 1999 and 2006. The estimated PDS treatment effect is smaller for this definition of treatment, but there are still statistically significant reductions in land allocated to consumption crops for the average household and significant reductions in land allocated to grains and consumption crops and days worked on the farm for households at the 90th percentile of initial share of agricultural output consumed.

In Appendix Table A I consider two additional specifications. The first includes an interaction of the value of non-PDS government programs with the initial share of agricultural output consumed. This provides a check on the potential confounding effect of other government programs targeted at poor households and allows for an independent assessment of whether these programs affected production outcomes in a similar fashion to the PDS. The second specification includes a measure of agricultural risk interacted with PDS value to assess whether households that face higher risk respond more strongly to PDS transfers. Risk could be an important mechanism behind high shares of home consumption and marketization costs. The risk measure is based on total reported household expenditures and losses due to agriculture-relevant shocks between 1999 and 2006, and include village-level shocks (crop failure, pests, droughts, well failure) and household level shocks (crop failure, price increases, irrigation well failure).${ }^{18}$ For both specifications, I find that the effects

\footnotetext{
${ }^{18}$ These make up over $70 \%$ of reported losses due to shocks, but results are similar including all
} 
of PDS expansion and the interaction with share of output consumed remain similar in magnitude and statistical significance for the land allocation outcomes. However, the value of other government programs does seem to have a negative direct effect and positive interaction coefficient with respect to land allocated to grains, agricultural net income and agricultural inputs.

\subsection{District-level effects (1993-2009)}

To assess district-level general equilibrium effects of PDS expansion, I use the NSS data to construct measures of the quantity and implicit value of PDS transfers per capita that can be matched to production data from ICRISAT. I focus on rural areas of districts because of my focus on agricultural production and because the 50th NSS round (1993) only contains district identifiers for the rural sample. ${ }^{19}$ I also examine heterogeneity across districts by interacting PDS quantity with proxies for local marketization costs in 1993 - the average share of food consumption out of ownproduction for farmers, road density, and rural bank branches per capita. These measures are all correlated (Figure 5) but may capture different aspects of marketization costs and the degree of agricultural consumption-production linkage they engender. I also consider a measure of openness to trade with other districts based on highway travel times to sources of agricultural trade. ${ }^{20}$

For the average district, PDS quantity (in monthly kilograms per capita) rises from 1.06 to 2.15 between 1993 and 2009, while the implicit value of the transfer rises from

of the other sources of losses reported including violence, theft, plant closures/job loss, other natural disasters, and household death and health shocks.

${ }^{19}$ Results are broadly similar using district level PDS measures that include urban areas and restricting to the 1999-2009 data. This is expected given that $75 \%$ of the population in the average district is rural. In Appendix Table A9 I report some state-level results that pool rural and urban areas (including major city districts that would otherwise be excluded from my analysis like Mumbai, Kolkata, Chennai, etc.) that are quantitatively similar.

${ }^{20}$ Specifically, I use the measure of travel time across districts from Allen and Atkin (2016) who digitize highway maps and use an algorithm to estimate a bilateral matrix of minimum travel times. I combine this with a measure of the value of agricultural output from each district from the ICRISAT district data, based on the idea that what matters from the perspective of agricultural trade is market access to other sources of agricultural output. I construct a weighted market access measure for each district $j$ given by $M k t a c c e s s_{j t}=\sum_{i n e q j} \frac{\operatorname{val}_{i t}}{h o u r s_{i j t}^{15}}$. The value of agricultural output in each district is based on combining output and harvest prices from the ICRISAT for major crops. Allen and Atkin (2016) calculate an inter-district highway travel time in hours that varies over time as the Indian highway system expands during select years of the sample period. I linearly interpolate the travel times for missing years but use actual annual output values from ICRISAT. The coefficient 1.5 is based on the estimate in Allen and Atkin (2016). 
1.88 to 9.16 (in 1993 rupees per capita). As highlighted in Figure 6, there is substantial variation in the quantity and implicit value of the expansion of PDS entitlements between 1993 and 2009 across states. The key identifying assumption is that conditional on district and year fixed effects, PDS expansion over this period is exogenous with respect to other factors that might affect the agricultural outcomes of interest. There were several phases of national expansion, with larger increases in quantities between 1999-2004 and larger increases in value (given quantities) between 2004-2009. States had very different levels of allotment (based on historical usage and the initial BPL estimates and by 2009 revised BPL criteria), offtake, targeting, accessibility and availability of entitlements on the ground, and different quantity and pricing schemes. This makes it plausible that within-district variation in PDS quantities and per unit subsidies during this period was based on administrative and political factors rather than economic factors relevant for agriculture. To account for the most obvious economic factors that could have affected expansion, I also control for district-level time-varying factors such as the rural population, fraction of households below the poverty line, real per capita monthly expenditures (in 1993 rupees), fraction of households using MNREGA (in 2009), and time-varying roads, rural bank branches and openness. At the state level I can also control for PDS procurement per capita which has general equilibrium effects that go in the opposite direction of PDS expansion (as the government's minimum support price must be higher than the counter-factual market price to ensure procurement). For robustness checks I will later consider additional controls to deal with endogeneity and potential confounding factors at the risk of absorbing most of the variation in my sample - district time-trends and state-year fixed effects.

I begin with regressions exploring the effect of PDS expansion on prices, the main channel for general equilibrium effects. I use the three sources of rice and wheat selling price data from Table 1. There are limitations to these price data, as they do not capture the full menu of prices facing farmers given that prices vary with seasons, quality, and where/to whom the output is sold, and they may mask substantial heterogeneity across villages (particularly those that are more remote). But they provide an important indication of whether PDS expansion resulted in large price effects and consequently large general equilibrium effects on production through the price channel.

Table 5 presents the results of this analysis. The main finding is that while the 
price effects of increases in PDS quantities are mostly negative, they are quite small and not statistically significant for selling prices. There is a larger and more significant negative effect on market buying prices. The positive income effects from changes in the PDS value (conditional on PDS quantity) are also statistically significant for market prices, although the correlation of PDS value and market prices should be interpreted with caution since PDS value is constructed using the difference between PDS and market prices. There is strong evidence that procurement of PDS grains increases selling prices (rice for NSS and ICRISAT prices, wheat for ICRISAT prices) as intended.

Overall, the price results are consistent with general equilibrium effects from PDS expansion that go in the expected direction but that are modest from the perspective of farmers maximizing the market value of their crop output. This is likely due to some combination of relative openness of wholesale trade between districts, government procurement preventing large effects on selling prices, and some attenuation from income effects. Since market purchase prices appear to decrease more than selling prices, marketization costs decrease for all households in the district, which could lead to further effects on production for households (including non PDS households) that now find it preferable to source their staples from the market. ${ }^{21}$ Appendix Table A5 presents results interacting the PDS quantity with measures of district-level heterogeneity; these indicate that the negative effects on market prices are slightly smaller in districts with low marketization costs but slightly larger in districts that are more open.

Turning to output effects, I examine the response of district-level yields of rice and wheat from the ICRISAT data to PDS expansion. While price data are aggregated and may not capture all of the relevant price signals facing farmers in a district, these output responses are representative at the district level and capture the net effect of both land and other input allocations. Table 6 presents results for rice (Panel A) and wheat (Panel B). Column 1 considers the average effect of PDS expansion across districts, and provides evidence of modest effects that are in line with the modest partial equilibrium effects identified in the ARIS/REDS data and the modest price changes observed earlier. A $1 \mathrm{KG}$ increase in PDS rice (wheat) quantity crowds out about about $0.05 \mathrm{KG}(0.1 \mathrm{KG})$ of rice (wheat) production. As expected procurement has a

\footnotetext{
${ }^{21}$ Aggregate decreases in home consumption of rice/wheat in Appendix Table A6) are larger than partial equilibrium decreases in Table 2, which is consistent with this mechiansm.
} 
large positive effect on local production. Increases in the value of PDS transfers (conditional on quantity) also have a significant negative effect on local rice and wheat production. This is more surprising given the positive effect on PDS value on consumption in the partial-equilibrium analysis, but district-level consumption results (Appendix Table A6) also show weaker effects of PDS value despite showing similar effects for changes in PDS quantity.

Columns 2 through 5 of Table 6 interact the PDS quantity with proxies for low marketization costs or openness at the beginning of the sample period (1993). I consider low marketization cost districts as those with below median average farmer home share of food consumption (column 2) or above median road density (column 3) or rural bank branches per capita (column 4), while high openness districts (column 5) are those with above median access to other agricultural markets. The main finding is that for rice, which is the more important PDS staple (over $70 \%$ of the combined quantity in 2009), we cannot reject that districts with low marketization costs (low farmer share of food, high road density, or high rural bank branches per capita) have a zero output effect of PDS expansion at conventional levels. Districts with high marketization costs have negative output effects for rice that are larger in magnitude (1 KG increase in PDS lowers output by $0.08 \mathrm{KG}$ ). Marketization costs do not seem to play as important a role for wheat and the interactions go in the wrong direction. Interestingly, areas with high openness also have larger output effects for rice and wheat which is consistent with larger empirical market price effects (Appendix Table A5) but at odds with the model if openness only matters through a smaller price response. Road density can also be interpreted as a measure of openness, at least for more remote areas within a district, in which case the evidence here is consistent with smaller (negative) general equilibrium effects on local prices for districts with high road density. Note that output effects of PDS expansion are robust to controlling for the district price measures earlier, which is further evidence that marketization costs or other mechanisms play an important mediating role.

Beyond output effects, the model predicts that PDS expansion under high marketization costs should lead to exit from farming, a decrease in the home share of food, and a shift in inputs towards more market-oriented crops when market crop productivity is high relative to staple crop productivity. Table 7 considers these outcomes at the district level. I use the ecological comparative advantage index introduced earlier to capture re-allocation of land to crops with higher relative productivity; an 
advantage of this index is that it weights land re-allocation from rice and wheat to other crops by relative productivity differences from the rest of India, such that decreases in rice and wheat (or other grain) land allocations could actually lower the index when a district has an ecological comparative advantage in these crops.

Table 7 shows that PDS expansion lowers the fraction of households that are classified as self-employed in agriculture (Panel A) and the share of food consumption out of home production (Panel B) by about 1.3 percentage points for each $\mathrm{KG} / \mathrm{month}$ /per capita of PDS grains. These effects are about double the size of the partial equilibrium effect in Table 2 and suggests that general equilibrium effects operating through the selling price of grains and/or the marketization cost wedge (which also depends on the buying price) are non-trivial. Given the approximately $1 \mathrm{KG} / \mathrm{month} /$ per capita increase between 1993-2009, these coefficients imply that about $30 \%$ of the decrease in share of rural households self-employed in agriculture and $20 \%$ of the decrease in the share of food consumption out of home production can be explained by PDS expansion. Columns 2 through 5 show that these effects are almost exclusively driven by districts with high marketization costs proxied by high shares of consumption out of home production for farmers or low road density. Panel C shows that expansion of PDS quantity leads to land re-allocations that increase exploitation of agro-ecological comparative advantage relative to the rest of India, with smaller effects in districts with low marketization costs but larger effects in districts with high openness. The magnitude is large relative to the average national changes in the ecological comparative advantage index over the sample period, equivalent to the decrease between 1993 to 2004 or the increase from 2004 to 2009, but is consistent with the relatively small effects on staple output and land allocations presented above.

Appendix Table A7 assesses the robustness of the average district-level results for market prices, output and agricultural specialization with respect to two distinct sources of potential endogeneity. In Panel A, I control for district linear time-trends, which account for a host of factors that could simultaneously affect agricultural production and PDS entitlements. As district fixed effects are already included and there are only four observations per district $(1993,1999,2004,2009)$, this is a very demanding specification, but I continue to find effects on rice market prices, rice quantities, share of farmers and share of food consumption out of home production that are similar in magnitude and statistically significant. The effects on wheat prices and the ecological comparative advantage index are not robust to district time trends. In 
Panel B, I control instead for state-year fixed effects, which account for a distinct set of factors including any changes in state-level policies that might be correlated with state-level PDS expansion; the identifying variation in PDS expansion in this case should be considered an interaction between state-level PDS policies and districtlevel heterogeneity (e.g. number of BPL households). This specification finds similar effects to Panel A, suggesting that the core set of district-level results are robust to a wide-variety of unobserved confounds.

Appendix Table A8 considers the effect of PDS expansion on other agricultural inputs using the ICRISAT district data. The model predicts a decrease in inputs into staple agriculture, but it is possible that switching to other crops requires more inputs, or that credit constrained households increase inputs due to the income effects of the PDS expansion. Appendix Table A8 suggests this is not the case, at least at an aggregate level, as the effect of PDS quantity expansion is close to zero for fertilizer, irrigation and livestock. For wells and tractors, the quantity effect is negative - consistent with lower inputs into agriculture - and the income effect is positive, which is also consistent with the model under marketization costs.

Appendix Table A9 revisits the effects of PDS expansion on rice/wheat output and farming from the perspective of states. Although this significantly reduces the sample variation (16 states and 4 years each) it has the advantage of capturing any within-state spillovers, including from urban areas. It also allows me to assess the extent to which PDS leakage, which is not observed in the NSS but is available at the state-level, plays any role. Columns 1 and 4 show that PDS quantity expansion results in similar decreases in grain output and the share of households that are selfemployed in agriculture using a state-level variation; the latter coefficient is no longer statistically significant but it also has a different interpretation since households that move to urban areas remain in the denominator and state-level shares are populationweighted district average shares. Columns 2 and 5 replace the PDS quantity variable with state offtake, which includes both the PDS quantities consumed (measured in the NSS) and leakage that could result from spoilage or theft/open-market diversion. Offtake per capita has a negative effect on rice/wheat output and farming but the magnitude is less than half of PDS quantity per capita and the coefficients are not statistically significant. Columns 3 and 6 include both PDS quantity and offtake, along with PDS value, and the results imply that it is the quantity of grains actually consumed from the PDS by households that matters most for agricultural production. 


\section{Conclusion}

Schultz (1953) identified the "food problem" as the combination of low agricultural productivity and high agricultural employment in developing countries, a problem that is compounded by international trade costs (which force poor countries to produce their own food) and domestic internal trade costs (which contribute to lower agricultural productivity through internal crop specialization or sectoral labor allocations). I argue that this "food problem" also operates at a household scale when rural households are poor and face high costs of transacting with markets, which incentivizes them to devote more land and labor inputs to staple food production for their own consumption. While the consumption advantage offered by staple production may be welfare maximizing for these households, in line with the classic literature on agricultural households, it can also lead to lower efficiency from a market perspective in terms of crop choices and input allocation. I show that an important implication of these facts is that in-kind transfer systems, like India's PDS, can directly affect production decisions for recipient households, particularly when households are confronted with the combination of poverty and high marketization costs. The production effects of the PDS expansion in India are modest in aggregate, in line with the modest size of PDS transfers and the fact that the largest, most productive and most market-oriented farmers are less affected. However, these production effects are still quantitatively important in settings where marketization costs and consumption out of own agricultural output are high, which is the case for at least some Indian households and is likely the case for many other developing countries with worse infrastructure and lower population density than India.

One limitation of this study is that I focus only on the production-side effects of India's PDS. A full evaluation of the program, from the perspective of social welfare or agricultural productivity, requires an accounting of additional benefits and costs of the program, which include the effects of PDS grain procurement, costs of government distribution and subsidy, and any additional benefits to households on the consumption side. I find some evidence that procurement at the state level raises prices and output, but making progress on a complete assessment of the system will require some combination of more and better data (including more granular data on PDS procurement, data on internal market and PDS trade, PDS finances) and model-imposed structure. Given ongoing policy debates about the costs of PDS procurement, reform-

ing the PDS and potentially transitioning to a more cash-based welfare system, this 
seems like a very fruitful area for more research. Another limitation of this study is that while I observe proxies for marketization costs and observe the implications of high marketization costs, I do not directly measure the size and specific nature of these costs. A better understanding of the size and nature of marketization costs, and the implications of different policy interventions or counter-factuals that reduce them, will also require some combination of more and better data and/or modelimposed structure. Given that home shares of consumption are observed in many developing country surveys and have an intuitive link to the trade literature (e.g. the relationship between the gains from trade versus autarky and home-produced shares of consumption in Arkolakis et al. (2012) type settings), integrating heterogeneous agricultural households into an aggregative general equilibrium trade model (along the lines of Bergquist et al. (2020)) seems like a promising direction for future research.

An important policy implication of my findings is that the costs incurred to distribute in-kind transfers, which are often viewed as inefficiencies relative to market provision, can deliver real benefits to poor households when markets do not serve them well. These benefits may go beyond consumption benefits and the convenience or security of purchasing goods from a large network of government ration shops mandated to serve even the most remote villages. My results suggest that in-kind food transfers could be a second best policy in the Indian context, at least for some households and locations, or in any setting where marketization costs exert large distortionary effects on rural production. Given the nature of food production - tied to the land and thus often located in low density, remote areas - poor rural households are particularly likely to be affected by high costs of transacting with markets, and policies that lower their incentive to produce staple goods for own consumption may contribute to increasing productivity by re-allocating inputs across crops, farms, and sectors. Future evaluations of cash vs. in-kind transfers and policy discussions related to reforming India's PDS should be particularly sensitive to production effects and productive efficiency for poor rural households facing high marketization costs.

\section{References}

Adamopolous, Tasso, "Spatial Integration and Agricultural Productivity: Quantifying the Impact of New Roads," Working Paper, 2020. 
- and Diego Restuccia, "The Size Distribution of Farms and International Productivity Differences," American Economic Review, 2014.

_ and _, "Land Reform and Productivity: A Quantitative Analysis with Micro Data," American Economic Journal: Macroeconomics, 2020.

_ , Loren Brandt, Jessica Leight, and Diego Restuccia, "Misallocation, Selection and Productivity: A Quantitative Analysis with Micro Data from China," Working Paper, 2019.

Allen, Treb, "Information Frictions in Trade," Econometrica, 2014, 82(6).

_ and David Atkin, "Volatility and the Gains from Trade," Working Paper, 2016.

Aragon, Fernando, Juan Pablo Rud, and Diego Restuccia, "Are Small Farms Really more Productive than Large Farms?," Working Paper, 2020.

Arkolakis, Costas, Arnaud Costinot, and Andres Rodriguez-Clare, "New Trade Models, Same Old Gains?," American Economic Review, 2012, 102(1), 94-130.

Atkin, David, "Trade, Tastes and Nutrition in India," American Economic Review, 2013, 103(5).

- and Dave Donaldson, "Who's Getting Globalized? The Size and Implications of Intranational Trade Costs"," Working Paper, 2015.

Balani, Sakshi, "Functioning of the Public Distribution System: An Analytical Report," PRS Legislative Research, 2013.

Basu, Deepankar and Debarshi Das, "Social Hierarchies and Public Distribution of Food in Rural India," Working Paper, 2014.

Bergquist, Lauren Falcao and Michael Dinerstein, "Competition and Entry in Agricultural Markets: Experimental Evidence from Kenya," American Economic Review, 2020, 110(12).

_, Benjamin Faber, Thibault Fally, Matthias Hoelzlein, Edward Miguel, and Andres Rodriguez-Clare, "Scaling Up Agricultural Policy Interventions: Theory and Evidence from Uganda," Working paper, 2020. 
Casaburi, Lorenzo, Rachel Glennerster, and Tavneet Suri, "Rural Roads and Intermediated Trade: Regression Discontinuity Evidence from Sierra Leone," Working Paper, 2013.

Chatterjee, Shoumitro, “Market Power and Spatial Competitin in Rural India," Working Paper, 2020, 129(2).

Commission, Planning, "Performance Evaluation of Targeted Public Distribution System (TPDS)," 2005.

Cunha, Jesse, "Testing Paternalism: Cash vs. In-kind Transfers," American Economic Journal: Applied, 2014, 6(2), 195-230.

_ , Giacomo De Giorgi, and Seema Jayachandran, "The Price Effects of Cash Versus In-Kind Transfers," Review of Economic Studies, 2019, 86(1).

Currie, Janet and Firouz Gahvari, "Transfers in Cash and In-Kind: Theory Meets the Data," Journal of Economic Literature, 2008, 46(2).

de Janvry, Alain and Elisabeth Sadoulet, "Progress in the modeling of rural households' behavior under market failures," in "Essays in Honor of Erik Thorbecke," Kluwer Publishing, 2006.

_ , Marcel Fafchamps, and Elizabeth Sadoulet, "Peasant Household Behaviour with Missing Markets: Some Paradoxes Explained," Economics Journal, 1991, 101, 14001417.

Donaldson, Dave, "Railroads of the Raj: Estimating the Impact of Transportation Infrastructure," American Economic Review, 2018, 108(4).

Dreze, Jean and Reetika Khera, "Rural Poverty and the Public Distribution System," CDE Working Paper, 2013.

Fafchamps, Marcel, "Cash Crop Production, Food Price Volatility, and Rural Market Integration in the Third World," American Journal of Agricultural Economics, 1992, 74(1), 90-99.

- and Ruth Vargas Hill, "Selling at the Farmgate or Traveling to Market," American Journal of Agricultural Economics, 2005, 87(3), 717-734. 
_ , Eleni Gabre-Madhin, and Bart Minten, "Increasing returns and market efficiency in agricultural trade," Journal of Development Economics, 2005, 78(2), 406-422.

Foster, Andrew and Mark Rosenzweig, "Labor-Market Transaction Costs, Machine Capacities and Optimal Farm Size," Working Paper, 2021.

Fulford, Scott, "The effects of financial development in the short and long run," Journal of Development Economics, 2013, 104, 56-72.

Gardenne, Lucie, "Can Rationing Increase Welfare? Theory and an Application to India's Ration Shop System," American Economic Journal: Policy, 2020, 12(4).

_ , Sam Norris, Monica Singhal, and Sandip Sukhtankar, "In-Kind Transfers as Insurance," Working Paper, 2021.

Ghatak, Maitreesh, Chinmaya Kumar, and Sandip Mitra, "Cash versus Kind: Understanding the Preferences of the Bicycle-Programme Beneficiaries in Bihar," Economics and Political Weekly, 2016, 51(11).

Ghosh, Madhusudan, "Agricultural policy reforms and spatial integration of food grain markets in India," Journal of Economic Development, 2011, 36(2), 225-250.

Gollin, Doug, David Lagakos, and Michael Waugh, "The Agricultural Productivity Gap," Quarterly Journal of Economics, 2014, 129(2).

Gollin, Douglas and Christopher Udry, "Heterogeneity, Measurement Error and Misallocation: Evidence from African Agriculture," Journal of Political Economy, 2021, 129(1).

- and Richard Rogerson, "Agriculture, Roads, and Economic Development in Uganda," NBER Working Paper 15863, 2010.

_ and _ , "Productivity, transport costs and subsistence agriculture," Journal of Development Economics, 2014.

Government of India Department of Food and Public Distribution, "Targeted Public Distribution System," website: https://dfpd.gov.in/pds-tpds.htm, 2021.

Hamory, Joan, Marieke Kleemans, Nicholas Y Li, and Edward Miguel, "Reevaluating agricultural productivity gaps with longitudinal microdata," Journal of the European Economic Association, 2017. 
Hirvonen, Kalle and John Hoddinott, "Beneficiary Views on Cash and In-Kind Payments: Evidence from Ethiopia's Productive Safety Net Programme," World Bank Economic Review, 2021, 35(2).

Karlan, Dean, Robert Osei, and Isaac Osei-Akoto, "Agricultural Decisions after Relaxing Credit and Risk Constraints," Quarterly Journal of Economics, 2014, 129(2).

Kaushal, Neeraj and Felix M. Muchomba, "How Consumer Price Subsidies affect Nutrition," World Development, 2015, 74, 25-42.

Khera, Reetika, "Revival of the Public Distribution System: Evidence and Explanations," Economic and Political Weekly, 2011, 46, 36-50.

_ , "Trends in Diversion of PDS Grain," CDE Working Paper 198, 2011.

Kochar, Anjini, "Can Targeted Food Programs Improve Nutrition? An Empirical Analysis of India's Public Distribution System," Economic Development and Cultural Change, 2005, pp. 203-235.

Krishnamurthy, Prasad, Vikram Pathania, and Sharad Tandon, "Food Price Subsidies and Nutrition: Evidence from State Reforms to India's Public Distribution System," Working Paper, 2014.

Kurosaki, Takashi and Marcel Fafchamps, "Insurance market efficiency and crop choices in Pakistan," Journal of Development Economics, 2002, 67(2), 419-453.

LaFave, Daniel and Duncan Thomas, "Farms, Families, and Markets: New Evidence on Completeness of Markets in Agricultural Settings," Econometrica, 2016, 84(5).

Lagakos, David and Michael Waugh, "Selection, Agriculture, and Cross-Country Productivity Differences," American Economic Review, 2013, 103(2).

Leemput, Eva Van, “A Passage to India: Quantifying Internal and External Barriers to Trade," Journal of International Economics, 2021.

Li, Nicholas, "An Engel Curve for Variety," Review of Economics and Statistics, 2021, 103(1), 72-87.

Mallory, Mindy and Kathy Baylis, "Food Corporation of India and the Public Distribution System: Impacts of Market Integration in Wheat, Rice, and Pearl Millet," Journal of Agribusiness, 2012, 30(2), 225-250. 
Morando, Bruno, "Market access and inefficient cropping patterns in Uganda," Working Paper, 2020.

_ , "Subsistence farming and factor misallocation: Evidence from Ugandan agriculture," Working Paper, 2020.

Murthy, Rajluxmi Vaish and T.V. Ramanayya, "Procurement Policy for Food Corporation of India: Modifications and Implications," IIM Bangalore Working Paper 250, 2007.

Omamo, Steven Were, "Transport Costs and Smallholder Cropping Choices: An Application to Siaya District, Kenya," American Journal of Agricultural Economics, 1998, 80, 116-123.

Planning Commission, "Chapter 3.4: Public Distribution System," Tenth Five Year Plan, 2002, 2.

Pulido, Jose and Thomasz Swiecki, "Barriers to Mobility or Sorting? Sources and Aggregate Implications of Income Gaps across Sectors in Indonesia," Working Paper, 2020.

Raghunathan, Siddharth Hari Kalyani, "Providing more than just employment? Evidence from the NREGA in India," Working Paper, 2016.

Restuccia, Diego, Dennis Tao Yang, and Xiaodong Zhu, "Agriculture and aggregate productivity: A quantitative cross-country analysis," Journal of Monetary Economics, 2008, 55(2), 234-250.

Rivera-Padilla, Alberto, "Crop choice, trade costs, and agricultural productivity," Journal of Development Economics, 2020, 146.

Schultz, T.W., The Economic Organization of Agriculture, New York: McGraw-Hill, 1953.

Singh, Inderjit, Lyn Squire, and John Strauss, Agricultural household models : extensions, applications, and policy (English)., World Bank Group, 1986.

Sivakul, Aganitpol, "Cash Versus In-Kind Transfers, The Case of Bangladesh," Working Paper, 2012. 
_ , "Comparing Cash and Voucher Transfers in a Humanitarian Context: Evidence from the Democratic Republic of Congo," World Bank Economic Review, 2017, 31(1), $44-70$.

Sotelo, Sebastian, "Domestic Trade Frictions and Agriculture," Journal of Political Economy, 2020, 128(7).

Tarozzi, Alessandro, “The Indian Public Distribution System as provide of food security: Evidence from child nutrition in Andhra Pradesh," European Economic Review, 2005, 49, 1305-1330.

Taylor, J. Edward and Irma Adelman, "Agricultural Household Models: Genesis, Evolution, and Extensions," Review of Economics of the Household, 2003.

Tombe, Trevor, "The Missing Food Problem: Trade, Agriculture, and International Productivity Differences," American Economic Journal: Macroeconomics, 2014. 


\section{Figures and Tables}

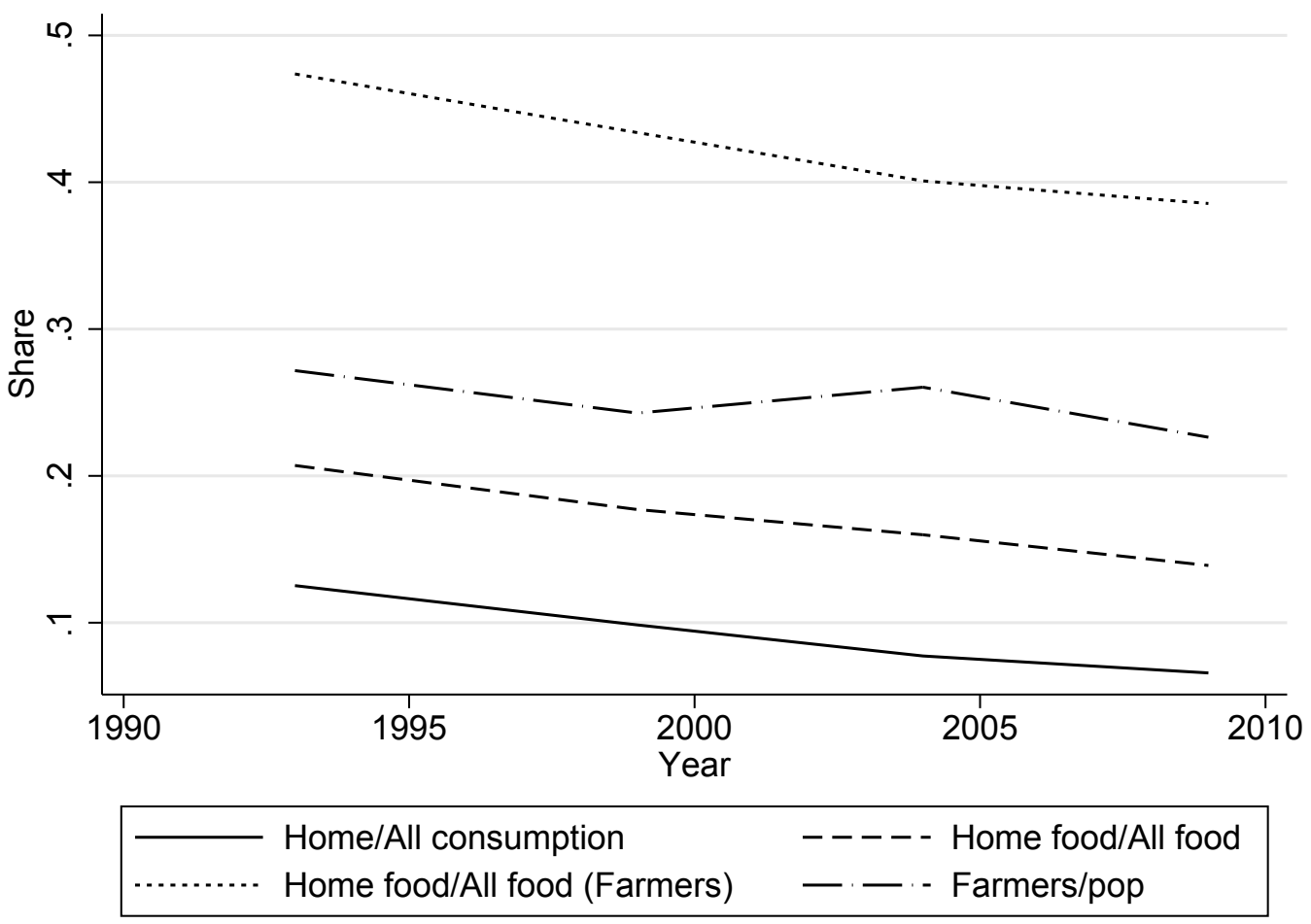

Figure 1: Home shares of consumption. Farmers defined as households with "selfemployed in agriculture" reported household type. Data come from NSS national aggregates for rounds 50,55, 61, and 66 and use sample weights. 

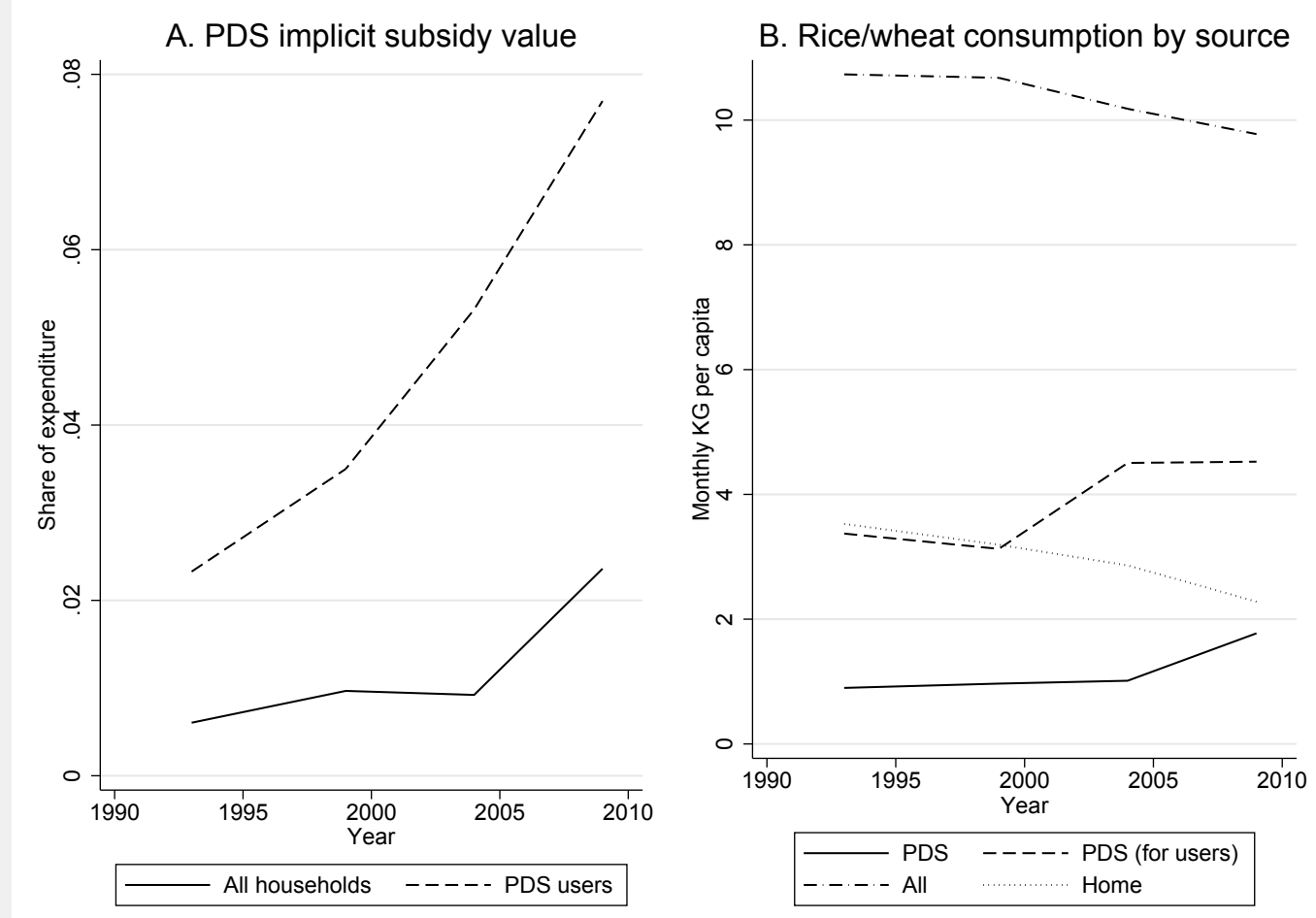

Figure 2: PDS expansion. Panel A estimates subsidy value by multiplying national PDS quantities by national gap between average market and PDS prices for rice and wheat, divided by national consumption expenditure (All households) or national consumption expenditure of households receiving PDS (PDS households). Panel B reports quantities per capita for all households or PDS households. Data come from NSS national aggregates for rounds 50,55, 61, and 66 and use sample weights. 


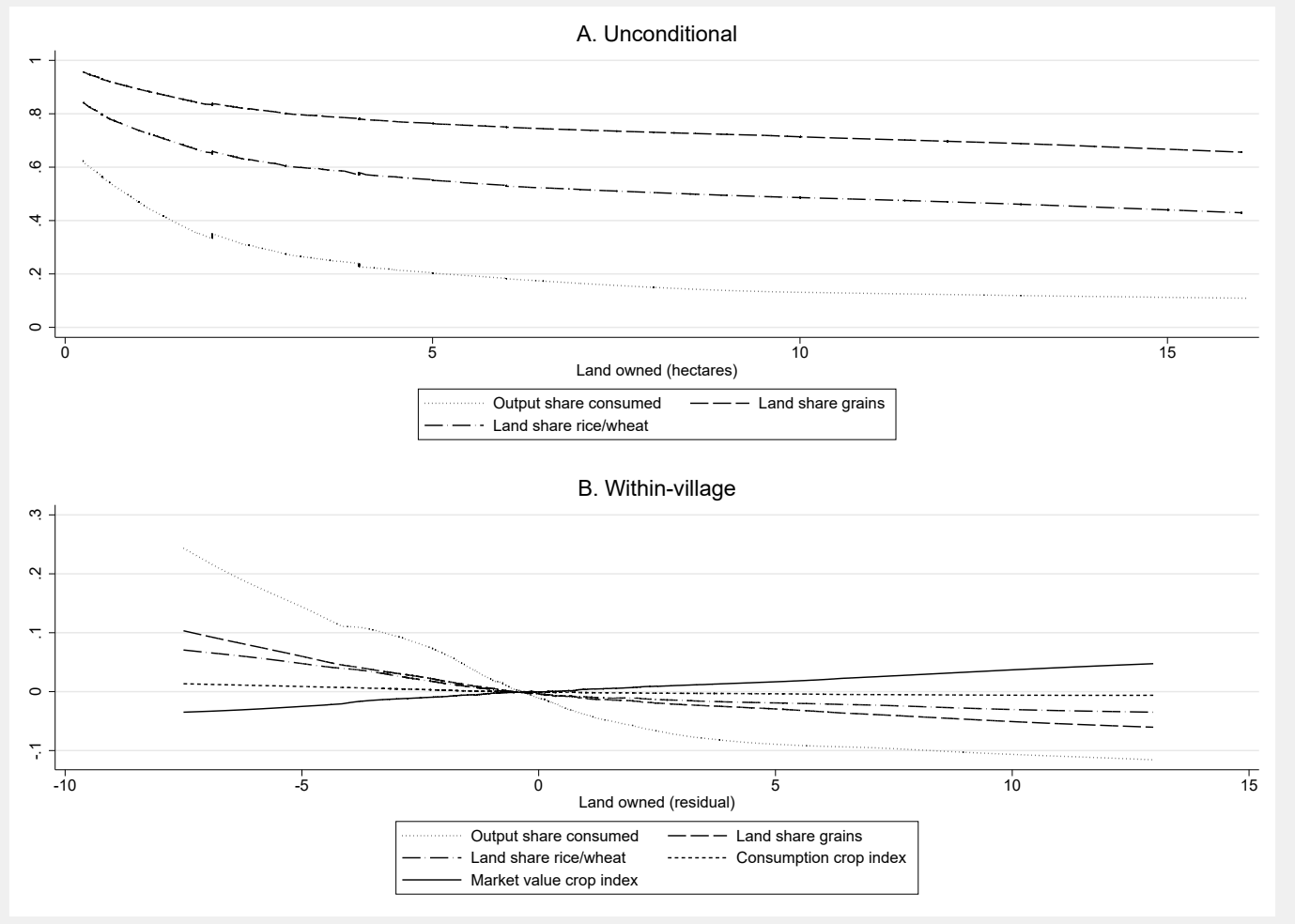

Figure 3: Staples, land allocation and land owned in ARIS/REDS 1999 data. Panel A presents locally weighted regression of the share of output consumed and share of land allocated to rice/wheat or all grains. Panel B is similar but partials out village fixed effects from the $\mathrm{Y}$ and $\mathrm{X}$ variables. Consumption crop index is the land share weighted sum of each crops aggregate share consumed at home. Market value crop index is the land share weighted sum of village aggregate revenue/acre of each crop. 

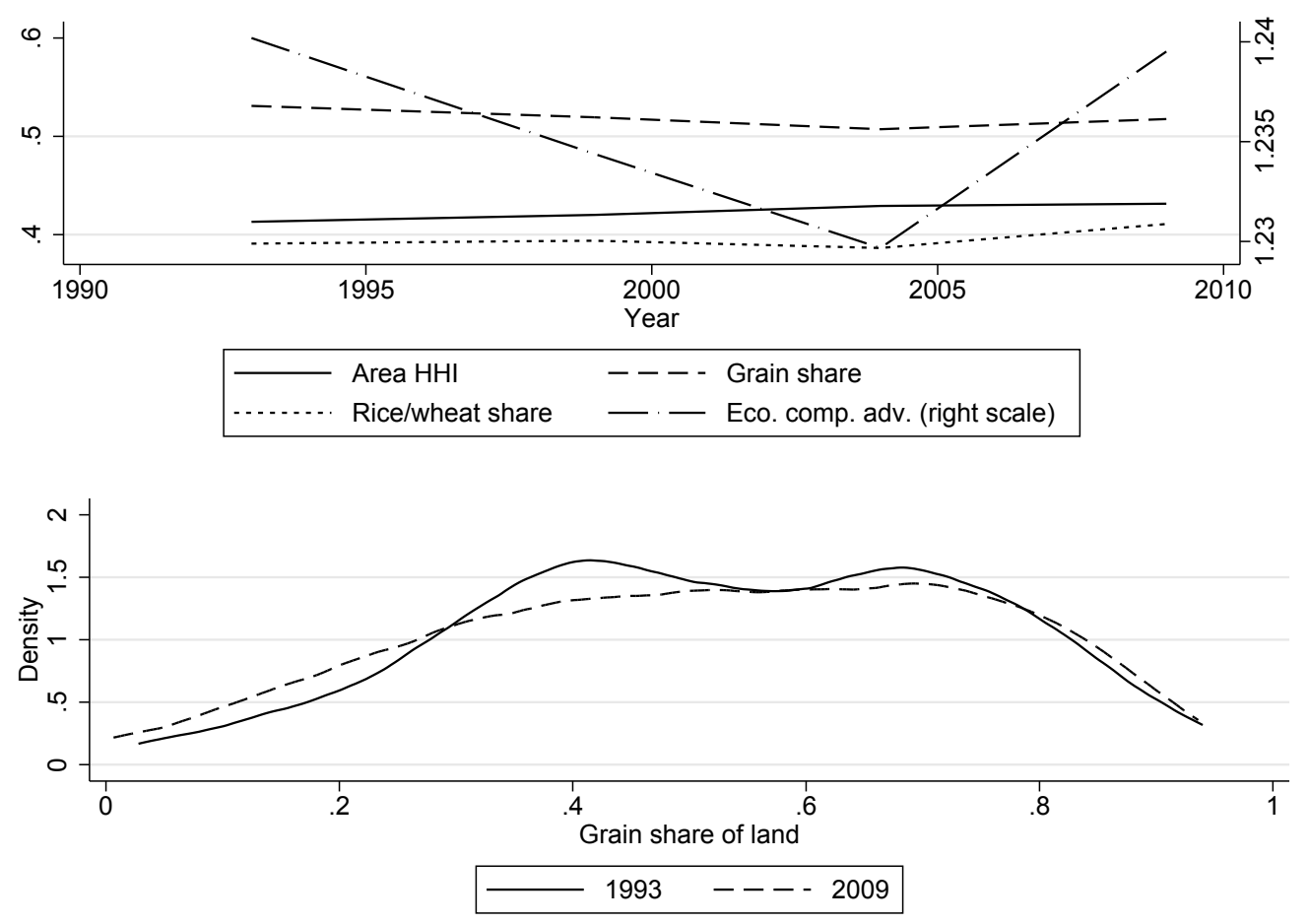

Figure 4: Specialization at the district level. Top panel uses data from ICRISAT district data on area cultivated for 16 reported crops divided by total area cultivated for these crops and reports the mean across districts for 1993, 1999, 2004, and 2009. Ecological comparative advantage (Eco. comp. adv.) also uses FAO/GAEZ data on intermediate input potential crop yields (see text for details on index construction). Bottom panel reports kernel density estimate of district-level share of land allocated to grains. 

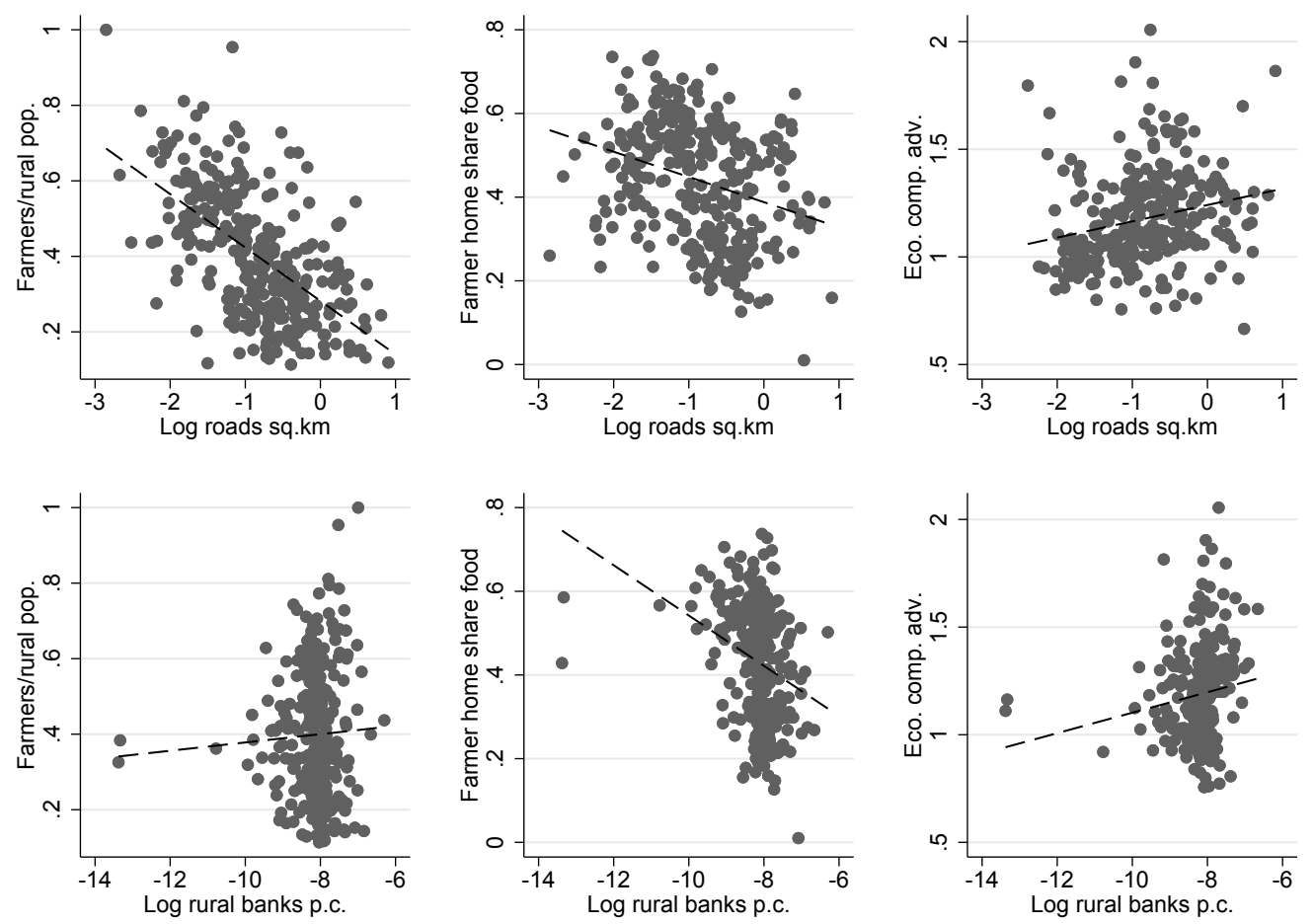

Figure 5: Relationship between roads, credit and marketization outcomes. Farmers/rural population calculated based on census data and interpolations. Average farmer home share of food from NSS. Ecological comparative advantage (Eco. comp. adv.) is described in the text and uses ICRISAT district data on land allocations with FAO/GAEZ potential crop yields. Road density is from ICRISAT district data. Rural bank branches per capita is from Fulford (2013). Dashed line is regression line fit (all correlations have $p<0.1$ ). 

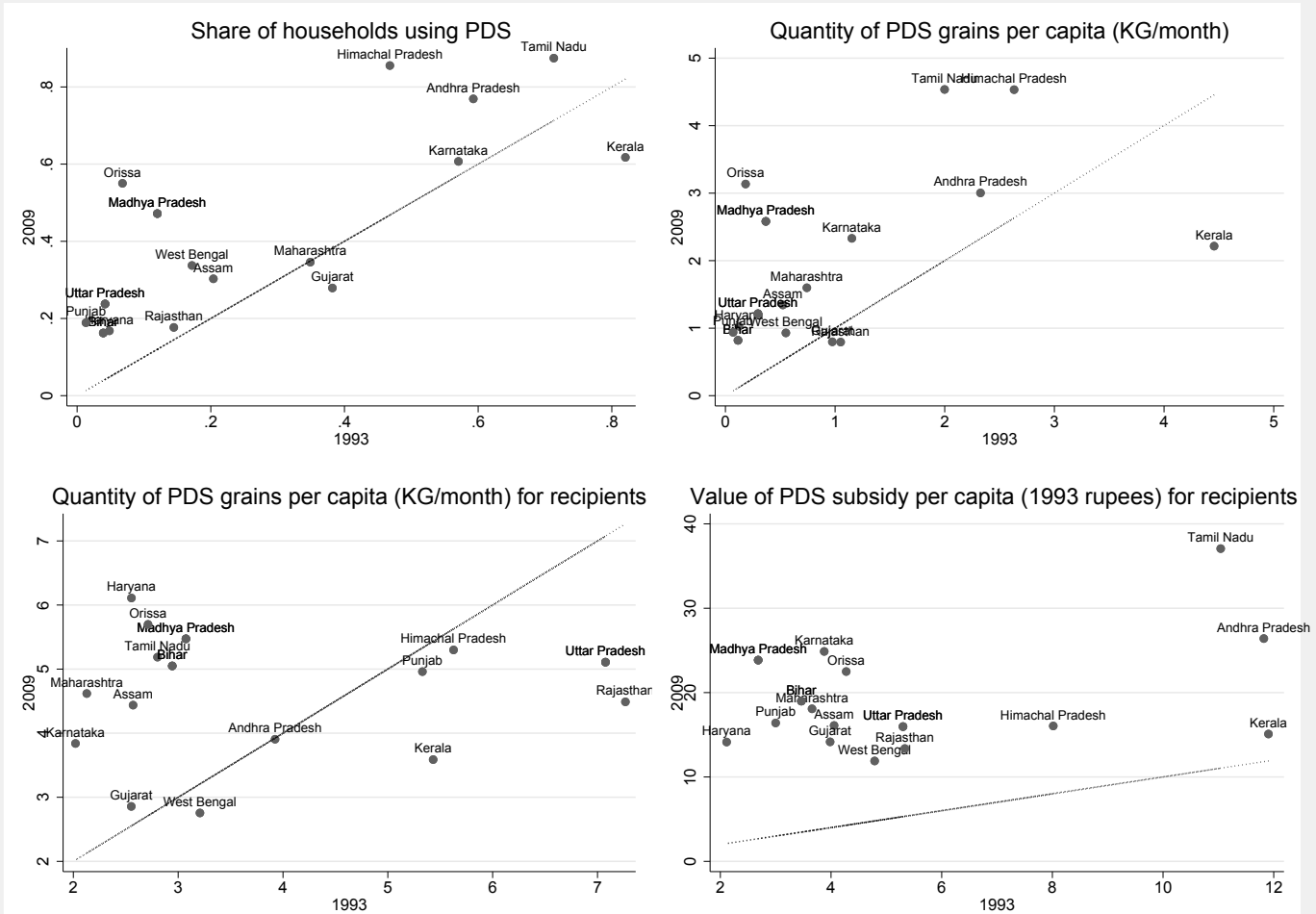

Figure 6: PDS variation across states. 45 degree line plotted. All data come from NSS rounds 50 and 66 . Value of PDS subsidy is calculated based on state-level total PDS quantity and state-level gap between average market and PDS price (divided by number of state PDS recipients). 


\section{Table 1: Buying and selling price gaps within and across districts}

\begin{tabular}{|c|c|c|c|c|c|c|c|c|}
\hline \multirow[b]{4}{*}{ Selling price source } & \multicolumn{4}{|c|}{ 1993-94 } & \multicolumn{4}{|c|}{$2009-10$} \\
\hline & \multicolumn{2}{|c|}{ Mean within district } & \multicolumn{2}{|c|}{ 75th / 25th pctile districts } & \multicolumn{2}{|c|}{ Mean within district } & \multicolumn{2}{|c|}{ 75th/25th pctile districts } \\
\hline & Buy/sell & Buy/sell & Buy & Sell & Buy/sell & Buy/sell & Buy & Sell \\
\hline & NSS & ICRISAT & & ICRISAT & NSS & ICRISAT & & ICRISAT \\
\hline Rice & 1.15 & 1.33 & 1.33 & 1.29 & 1.11 & 1.21 & 1.38 & 1.26 \\
\hline Wheat & 1.15 & 1.14 & 1.50 & 1.19 & 1.25 & 1.14 & 1.50 & 1.17 \\
\hline Sorghum & 1.10 & 1.03 & 1.33 & 1.38 & 1.15 & 1.21 & 1.40 & 1.23 \\
\hline Pearl millet & 1.11 & 1.11 & 1.33 & 1.35 & 1.12 & 1.22 & 1.36 & 1.24 \\
\hline Maize & 1.09 & 1.20 & 1.33 & 1.34 & 1.13 & 1.43 & 1.60 & 1.20 \\
\hline Finger millet & 1.06 & 1.14 & 1.40 & 1.24 & 1.20 & 1.34 & 1.64 & 1.12 \\
\hline Barley & 1.01 & 1.61 & 3.44 & 1.27 & 1.24 & 1.55 & 3.30 & 1.20 \\
\hline Gram & 1.22 & & 1.14 & & 1.19 & & 1.11 & \\
\hline Chickpea & 1.13 & 1.62 & 1.13 & 1.23 & 1.18 & 1.67 & 1.14 & 1.31 \\
\hline Pigeon Pea & 1.20 & 1.70 & 1.25 & 1.26 & 1.19 & 1.97 & 1.27 & 1.14 \\
\hline Groundnut & 1.34 & 1.99 & 1.33 & 1.23 & 1.36 & 2.14 & 1.20 & 1.25 \\
\hline Average & 1.14 & 1.39 & 1.50 & 1.28 & 1.19 & 1.49 & 1.54 & 1.21 \\
\hline
\end{tabular}

Buying prices are median rural district unit values for market purchases derived from NSS. NSS selling prices are median rural district unit values for imputed value of consumption out of home production (based on ex-farm gate prices). ICRISAT prices are the wholesale/mandi harvest prices reported in the district dataset (not reported for Gram). 
Table 2: NSS household consumption outcomes and PDS entitlements (within village). All quantities in kilograms per person per month.

\begin{tabular}{|c|c|c|c|c|c|c|c|c|}
\hline & $(1)$ & $(2)$ & (3) & (4) & (5) & (6) & (7) & $(8)$ \\
\hline Dep. var. & Rice/wheat & Mkt. rice/wheat & Home rice/wheat & Home share & Farmer dummy & Home rice/wheat & Home share & Home share \\
\hline & \multicolumn{5}{|c|}{ All rural households } & \multicolumn{3}{|l|}{ Farmers only } \\
\hline & \multicolumn{8}{|c|}{ Panel A: Comparing households with BPL (Below Poverty Line) cards to others (2004-2005) } \\
\hline \multirow[t]{2}{*}{ BPL card } & $0.741^{* * *}$ & $-0.772^{* * *}$ & $-1.039^{* * *}$ & $-0.041^{* * *}$ & $-0.118^{* * *}$ & $-0.776^{* * *}$ & $-0.017^{* * *}$ & $-0.013^{* *}$ \\
\hline & $(0.053)$ & $(0.144)$ & $(0.089)$ & $(0.003)$ & $(0.007)$ & $(0.149)$ & $(0.006)$ & $(0.006)$ \\
\hline \multirow[t]{2}{*}{ BPL card * poor } & & & & & & & & -0.013 \\
\hline & & & & & & & & $(0.010)$ \\
\hline Observations & 66,857 & 66,857 & 66,857 & 66,857 & 66,857 & 22,633 & 22,633 & 22,633 \\
\hline \multicolumn{9}{|c|}{ Panel B: Variation in quantity and value of PDS entitlements (1993-2009) } \\
\hline \multirow[t]{2}{*}{ PDS quantity } & $0.310^{* * *}$ & $-0.459^{* * *}$ & $-0.230^{* * *}$ & $-0.004^{* * *}$ & $-0.007^{* * *}$ & $-0.366^{* * *}$ & $-0.010^{* * *}$ & $-0.009^{* * *}$ \\
\hline & $(0.020)$ & $(0.019)$ & $(0.015)$ & $(0.001)$ & $(0.001)$ & $(0.035)$ & $(0.001)$ & $(0.001)$ \\
\hline \multirow[t]{2}{*}{ PDS quant. * poor } & & & & & & & & $-0.007^{* * *}$ \\
\hline & & & & & & & & $(0.001)$ \\
\hline \multirow[t]{2}{*}{ PDS value } & $0.035^{* * *}$ & $-0.010^{* *}$ & $0.045^{* * *}$ & 0.000 & $0.002^{* * *}$ & $0.019^{* *}$ & $0.001^{* * *}$ & $0.001^{* * *}$ \\
\hline & $(0.005)$ & $(0.004)$ & $(0.004)$ & $(0.000)$ & $(0.000)$ & $(0.009)$ & $(0.000)$ & $(0.000)$ \\
\hline Observations & 239,549 & 239,549 & 239,549 & 239,549 & 239,549 & 84,531 & 84,531 & 84,531 \\
\hline
\end{tabular}

Standard errors clustered by district in parentheses. ${ }^{* *} \mathrm{p}<0.01,{ }^{* *} \mathrm{p}<0.05,{ }^{*} \mathrm{p}<0.10$. Value of PDS transfer is measured as the difference between what the household paid for its PDS consumption and the cost of acquiring the same quantity at market prices (median village where available, median state where this is missing), measured per capita and deflated to 1993 rupees using all-India CPI. "Poor" farmers are defined as those with real per capita expedenditures below the sample median for farmers. per capita and deflated to 1993 rupees using all-India CPI. "Poor" farmers are defined as those with real per capita expedenditures below the sample median for farmers.
All regressions include village fixed effects and dummies for household size, household head education and gender, religion, scheduled caste and scheduled tribe status, as well as demographic ratios (fraction of adult and senior males and females), and quadratic in log real per capita expenditure (1993 rupees). Regressions for farmers also include a quadratic in log land possessed. The regressions in Panel B also control for all interactions between state dummies, year dummies, and a dummy for non-zero PDS. 
Table 3: ARIS/REDS household production effects and value of PDS entitlements (within household).

\begin{tabular}{|c|c|c|c|c|c|c|c|c|}
\hline & (1) & $(2)$ & (3) & (4) & (5) & (6) & (7) & (8) \\
\hline Dep. var. & Area rice/wheat & Area grains & Cons. crop & Mkt. crop & Ln(net ag. inc.) & Ln(net inc.) & Days ag. & Ln(mkt. inputs) \\
\hline \multicolumn{9}{|c|}{ Panel A: Average effects } \\
\hline \multirow[t]{2}{*}{ PDS value } & $-0.013^{* * *}$ & $-0.012^{* * *}$ & $-0.002^{* * *}$ & 0.004 & 0.013 & -0.019 & -5.116 & 0.013 \\
\hline & $(0.004)$ & $(0.004)$ & $(0.001)$ & $(0.003)$ & $(0.024)$ & $(0.020)$ & $(4.163)$ & $(0.016)$ \\
\hline Observations & 4,067 & 4,067 & 4,068 & 4,068 & 4,036 & 4,203 & 4,304 & 4,053 \\
\hline \multicolumn{9}{|c|}{ Panel B: Heterogeneity by share of agr. output consumed in 1999} \\
\hline \multirow[t]{2}{*}{ PDS value } & -0.006 & -0.001 & -0.001 & -0.001 & -0.024 & -0.044 & -6.376 & 0.005 \\
\hline & $(0.005)$ & $(0.005)$ & $(0.001)$ & $(0.005)$ & $(0.035)$ & $(0.033)$ & $(7.907)$ & $(0.033)$ \\
\hline \multirow[t]{2}{*}{ PDS value * share } & $-0.015^{* *}$ & $-0.021^{* * *}$ & $-0.003^{* * *}$ & 0.009 & $0.075^{*}$ & 0.054 & 2.735 & 0.017 \\
\hline & $(0.007)$ & $(0.008)$ & $(0.001)$ & $(0.006)$ & $(0.044)$ & $(0.047)$ & $(9.927)$ & $(0.045)$ \\
\hline Effect 90th pct. share (p) & 0.000 & 0.000 & 0.000 & 0.001 & 0.087 & 0.789 & 0.188 & 0.223 \\
\hline Observations & 4,067 & 4,067 & 4,068 & 4,068 & 4,036 & 4,203 & 4,304 & 4,053 \\
\hline \multicolumn{9}{|c|}{ Panel C: Heterogeneity by land owned in 1999} \\
\hline \multirow[t]{2}{*}{ PDS value } & $-0.014^{* * *}$ & $-0.017^{* * *}$ & $-0.003^{* * *}$ & $0.009^{* * *}$ & 0.038 & -0.010 & -6.504 & $0.039^{*}$ \\
\hline & $(0.004)$ & $(0.004)$ & $(0.001)$ & $(0.002)$ & $(0.025)$ & $(0.023)$ & $(4.621)$ & $(0.020)$ \\
\hline \multirow[t]{2}{*}{ PDS value * land } & 0.001 & $0.002^{* *}$ & $0.000^{* *}$ & $-0.002^{* *}$ & -0.011 & -0.003 & 0.425 & $-0.010^{* *}$ \\
\hline & $(0.001)$ & $(0.001)$ & $(0.000)$ & $(0.001)$ & $(0.007)$ & $(0.004)$ & $(0.802)$ & $(0.005)$ \\
\hline Observations & 4,273 & 4,039 & 4,040 & 4,040 & 4,009 & 4,175 & 4,275 & 4,025 \\
\hline Effect 10th pct. land & 0.000 & 0.000 & 0.000 & 0.000 & 0.156 & 0.595 & 0.158 & 0.078 \\
\hline \multicolumn{9}{|c|}{ Panel D: Heterogeneity by both share consumed and land } \\
\hline \multirow[t]{2}{*}{ PDS value } & -0.005 & -0.010 & $-0.002^{*}$ & 0.010 & 0.020 & -0.037 & -10.310 & 0.070 \\
\hline & $(0.007)$ & $(0.008)$ & $(0.001)$ & $(0.006)$ & $(0.057)$ & $(0.043)$ & $(10.775)$ & $(0.056)$ \\
\hline \multirow[t]{2}{*}{ PDS value * share } & $-0.015^{* *}$ & -0.013 & -0.002 & -0.002 & 0.030 & 0.047 & 6.773 & -0.050 \\
\hline & $(0.008)$ & $(0.010)$ & $(0.002)$ & $(0.008)$ & $(0.064)$ & $(0.054)$ & (12.488) & $(0.067)$ \\
\hline \multirow[t]{2}{*}{ PDS * land } & -0.000 & 0.002 & 0.000 & $-0.002^{* *}$ & -0.009 & -0.001 & 0.635 & $-0.013^{*}$ \\
\hline & $(0.001)$ & $(0.001)$ & $(0.000)$ & $(0.001)$ & $(0.009)$ & $(0.005)$ & $(0.987)$ & $(0.007)$ \\
\hline Observations & 4,039 & 4,039 & 4,040 & 4,040 & 4,009 & 4,175 & 4,275 & 4,025 \\
\hline R-squared & 0.929 & 0.845 & 0.856 & 0.876 & 0.899 & 0.824 & 0.786 & 0.902 \\
\hline Adj R-squared & 0.815 & 0.593 & 0.623 & 0.677 & 0.732 & 0.560 & 0.483 & 0.742 \\
\hline Effect 90th pct. share & 0.000 & 0.000 & 0.000 & 0.488 & 0.528 & 0.742 & 0.304 & 0.843 \\
\hline Effect 10th pct. land & 0.137 & 0.051 & 0.016 & 0.057 & 0.616 & 0.400 & 0.294 & 0.191 \\
\hline
\end{tabular}

Standard errors clustered by village-year in parentheses. ${ }^{* *} \mathrm{p}<0.01,{ }^{* *} \mathrm{p}<0.05,{ }^{*} \mathrm{p}<0.10$. Sample is all households with positive consumption out of agricultural output in 1999. Value of PDS is self-reported in 1000s of 2006 rupees (imputed from recall for 1999). All regressions include household fixed effects and village-year dummies. Additional controls include household size and household size squared, land owned and land owned squared, and the value of all other government programs received by the household. The consumption crop index (cons. crop) weights each household crop area share by the crop's aggregate share of output consumed. The market value crop index (mkt. crop) weights each household crop area share by the crop's average value of output per hectare for the village. Net agricultural income is the total value of crops produced (including consumed those consumed) minus the cost of seeds, fertilizers, pesticides, hired machinery, and irrigation. Net income includes net agricultural income as well as wage and salary income and net income from non-agricultural enterprises. Days agr. work refers to total days of work on the household's farm, including family and hired labor. The cost of agricultural inputs is the cost of seeds, fertilizers, pesticides, hired machinery, and irrigation purchased from the market. 


\section{Table 4: ARIS/REDS household production effects and intensive/extensive margin of PDS expansion (within household).}

\begin{tabular}{|c|c|c|c|c|c|c|}
\hline & (1) & $(2)$ & (3) & $(4)$ & (5) & (6) \\
\hline Dep. var. & Area grains & Consumption crop index & Market value crop index & Ln(net agr. inc.) & Ln(net income) & Days agr. work \\
\hline \multicolumn{7}{|c|}{ Panel A: PDS dummy in 2006} \\
\hline \multirow[t]{2}{*}{ PDS in 2006} & $-0.058^{*}$ & $-0.011^{* *}$ & -0.002 & -0.032 & -0.056 & $-73.121^{* * *}$ \\
\hline & $(0.030)$ & $(0.005)$ & $(0.016)$ & $(0.121)$ & $(0.115)$ & $(25.838)$ \\
\hline Observations & 4,067 & 4,068 & 4,068 & 4,036 & 4,203 & 4,304 \\
\hline \multicolumn{7}{|c|}{ Panel B: PDS dummy in 2006 and heterogeneity by share of agr. output consumed in 1999} \\
\hline PDS in 2006 & -0.008 & -0.002 & -0.028 & $-0.372^{* * *}$ & $-0.256^{* *}$ & -43.908 \\
\hline \multirow{3}{*}{ PDS in $2006^{*}$ share cons. } & $(0.037)$ & $(0.007)$ & $(0.019)$ & $(0.136)$ & $(0.126)$ & (33.708) \\
\hline & $-0.169 * * *$ & $-0.031^{* * *}$ & $0.086^{* * *}$ & $1.154^{* * *}$ & $0.655^{* *}$ & $-95.088^{*}$ \\
\hline & $(0.060)$ & $(0.010)$ & $(0.030)$ & $(0.239)$ & $(0.257)$ & $(56.565)$ \\
\hline Effect at 90th pct. share $=0$ (p-value) & 0.001 & 0.000 & 0.085 & 0.006 & 0.223 & 0.001 \\
\hline Observations & 4,067 & 4,068 & 4,068 & 4,036 & 4,203 & 4,304 \\
\hline
\end{tabular}

Standard errors clustered by village-year. ${ }^{* *} \mathrm{p}<0.01,{ }^{* *} \mathrm{p}<0.05,{ }^{*} \mathrm{p}<0.10$. Sample is all households with positive consumption out of agricultural output in 1999 . Al regressions include household fixed effects and village-year dummies. Additional controls include household size and household size squared, land owned and land owned squared, and the value of all other government programs received by the household. The consumption crop index weights each household crop area share by the crop's aggregate share of output consumed. The market value crop index weights each household crop area share by the crop's average value of output per hectare the crop's aggregate share of output consumed. The market value crop index weights each household crop area share by the crop's average value of output per hectare
for the village. Net agricultural income is the total value of crops produced (including consumed those consumed) minus the cost of seeds, fertilizers, pesticides, hired machinery, and irrigation. Net income includes net agricultural income as well as wage and salary income and net income from non-agricultural enterprises. Days agr work refers to total days of work on the household's farm, including family and hired labor.

Table 5: Rice and wheat prices: district-level effects of PDS expansion (rural India 1993-2009)

\begin{tabular}{|c|c|c|c|c|c|c|}
\hline \multirow[b]{3}{*}{ Source } & (1) & (2) & (3) & (4) & (5) & (6) \\
\hline & \multicolumn{3}{|c|}{ Rice prices } & \multicolumn{3}{|c|}{ Wheat prices } \\
\hline & NSS Farm-gate & NSS Mkt. & ICRISAT Harvest & NSS Farm-gate & NSS Mkt. & ICRISAT Harvest \\
\hline \multirow[t]{2}{*}{ PDS quantity per capita } & -0.005 & $-0.042^{* * *}$ & -0.007 & 0.011 & $-0.024^{* * *}$ & -0.013 \\
\hline & $(0.013)$ & $(0.008)$ & $(0.014)$ & $(0.010)$ & $(0.008)$ & $(0.008)$ \\
\hline \multirow[t]{2}{*}{ PDS value per capita } & -0.000 & $0.012^{* * *}$ & $0.008^{* *}$ & $-0.010^{* * *}$ & $0.006^{* * *}$ & 0.001 \\
\hline & $(0.003)$ & $(0.002)$ & $(0.003)$ & $(0.003)$ & $(0.002)$ & $(0.002)$ \\
\hline \multirow[t]{2}{*}{ PDS procurement per capita } & $0.011^{* *}$ & -0.003 & $0.016^{* * *}$ & 0.008 & $0.010^{* *}$ & $0.015^{* * *}$ \\
\hline & $(0.005)$ & $(0.003)$ & $(0.005)$ & $(0.005)$ & $(0.004)$ & $(0.004)$ \\
\hline Observations & 1,112 & 1,112 & 835 & 1,112 & 1,112 & 831 \\
\hline
\end{tabular}

Standard errors clustered by district in parentheses. ${ }^{* *} \mathrm{p}<0.01,{ }^{* *} \mathrm{p}<0.05,{ }^{*} \mathrm{p}<0.10$. Regressions include district and year fixed effects, and time-varying district level measures of population, fraction of households below the poverty line, real per capita monthly expenditure, openness (distance to agricultural output weighted by highway travel times), rural bank branches per capita, road density, and use of NREGA. NSS farm-gate and market prices are median unit values for rural households in the district based on consumption of out of home production and market purchases. PDS quantity per capita and PDS procurement per capita (reported at the state level) are in monthly KGs. PDS value per capita is the difference between the price paid for PDS grains in the district and the cost of purchasing the same quantities at district median market prices. 
Table 6: Rice and wheat output: district-level effects of PDS expansion (rural India 1993-2009)

\begin{tabular}{|c|c|c|c|c|c|}
\hline Low marketization cost & (1) & $\begin{array}{c}(2) \\
\text { Home share }\end{array}$ & $\begin{array}{c}(3) \\
\text { Roads }\end{array}$ & $\begin{array}{c}(4) \\
\text { Banks }\end{array}$ & $\begin{array}{c}(5) \\
\text { Open }\end{array}$ \\
\hline \multicolumn{6}{|c|}{ Panel A: Rice output (KG per capita per month) } \\
\hline \multirow{2}{*}{ PDS quantity per capita } & $-0.054^{* *}$ & $-0.079^{* * *}$ & $-0.085^{* * *}$ & $-0.077^{* *}$ & -0.036 \\
\hline & $(0.026)$ & $(0.027)$ & $(0.030)$ & $(0.034)$ & $(0.027)$ \\
\hline \multirow[t]{2}{*}{ PDS quant. ${ }^{*}$ Low mkt. cost } & & $0.059^{*}$ & $0.053^{*}$ & 0.039 & $-0.065^{*}$ \\
\hline & & $(0.033)$ & $(0.032)$ & $(0.033)$ & $(0.036)$ \\
\hline \multirow[t]{2}{*}{ PDS value per capita } & $-0.011^{* *}$ & $-0.013^{* * *}$ & $-0.011^{* * *}$ & $-0.011^{* *}$ & $-0.011^{* *}$ \\
\hline & $(0.004)$ & $(0.004)$ & $(0.004)$ & $(0.004)$ & $(0.004)$ \\
\hline \multirow[t]{2}{*}{ PDS procurement per capita } & $0.041^{* * *}$ & $0.043^{* * *}$ & $0.041^{* * *}$ & $0.040^{* * *}$ & $0.041^{* * *}$ \\
\hline & $(0.014)$ & $(0.014)$ & $(0.014)$ & $(0.014)$ & $(0.014)$ \\
\hline Observations & 1,112 & 1,112 & 1,112 & 1,110 & 1,112 \\
\hline \multicolumn{6}{|c|}{ Panel B: Wheat output (KG per capita per month) } \\
\hline \multirow[t]{2}{*}{ PDS quantity per capita } & $-0.094^{* * *}$ & $-0.075^{*}$ & $-0.085^{* * *}$ & -0.018 & $-0.052^{*}$ \\
\hline & $(0.027)$ & $(0.040)$ & $(0.029)$ & $(0.051)$ & $(0.027)$ \\
\hline \multirow[t]{2}{*}{ PDS quant. * Low mkt. cost } & & -0.036 & -0.075 & $-0.098^{*}$ & $-0.109^{*}$ \\
\hline & & $(0.056)$ & $(0.073)$ & $(0.058)$ & $(0.061)$ \\
\hline \multirow[t]{2}{*}{ PDS value per capita } & $-0.005^{*}$ & $-0.004^{*}$ & $-0.004^{*}$ & $-0.004^{*}$ & $-0.005^{* *}$ \\
\hline & $(0.002)$ & $(0.002)$ & $(0.002)$ & $(0.002)$ & $(0.002)$ \\
\hline \multirow[t]{2}{*}{ PDS procurement per capita } & $0.005^{* * *}$ & $0.005^{* * *}$ & $0.006^{* * *}$ & $0.005^{* * *}$ & $0.006^{* * *}$ \\
\hline & $(0.002)$ & $(0.002)$ & $(0.002)$ & $(0.002)$ & $(0.002)$ \\
\hline Observations & 1,098 & 1,098 & 1,098 & 1,098 & 1,098 \\
\hline
\end{tabular}

Standard errors clustered by district in parentheses. ${ }^{* * *} \mathrm{p}<0.01,{ }^{* *} \mathrm{p}<0.05,{ }^{*} \mathrm{p}<0.10$. Regressions include district and year fixed effects, and time-varying district level measures of population, fraction of households below the poverty line, real per capita monthly expenditure, openness (distance to agricultural output weighted by highway travel times), rural bank branches per capita, road density, and use of NREGA. PDS quantity per capita and PDS procurement per capita (reported at the state level) are in monthly KGs. PDS value per capita is the difference between the price paid for PDS grains in the district and the cost of purchasing the same quantities at district median market prices. "Home share" refers to districts with below median median shares of home-produced food for farmers in 1993. "Roads," "Banks," and "Open" refer to districts with above median values of these variables (defined above) in 1993. 
Table 7: Agricultural specialization outcomes: district-level effects of PDS expansion (rural India 1993-2009)

\begin{tabular}{|c|c|c|c|c|c|}
\hline Low marketization cost & $(1)$ & $\begin{array}{c}(2) \\
\text { Home share }\end{array}$ & $\begin{array}{c}(3) \\
\text { Roads }\end{array}$ & $\begin{array}{c}(4) \\
\text { Banks }\end{array}$ & $\begin{array}{c}(5) \\
\text { Open }\end{array}$ \\
\hline \multicolumn{6}{|c|}{ Panel A: Fraction of households "self-employed in agriculture" } \\
\hline \multirow{2}{*}{ PDS quantity per capita } & $-0.013^{* *}$ & $-0.021^{* * *}$ & $-0.018^{* * *}$ & -0.009 & -0.009 \\
\hline & $(0.006)$ & $(0.007)$ & $(0.007)$ & $(0.008)$ & $(0.006)$ \\
\hline \multirow[t]{2}{*}{ PDS quant ${ }^{*}$ Low mkt. cost } & & $0.017^{* *}$ & $0.015^{* *}$ & -0.005 & -0.011 \\
\hline & & $(0.008)$ & $(0.008)$ & $(0.007)$ & $(0.009)$ \\
\hline \multirow[t]{2}{*}{ PDS value per capita } & 0.000 & -0.000 & -0.000 & 0.000 & -0.000 \\
\hline & $(0.001)$ & $(0.001)$ & $(0.001)$ & $(0.001)$ & $(0.001)$ \\
\hline \multirow[t]{2}{*}{ PDS procurement per capita } & 0.001 & 0.002 & 0.001 & 0.001 & 0.002 \\
\hline & $(0.002)$ & $(0.002)$ & $(0.002)$ & $(0.002)$ & $(0.002)$ \\
\hline Observations & 1,112 & 1,112 & 1,112 & 1,110 & 1,112 \\
\hline \multicolumn{6}{|c|}{ Panel B: Home produced share of food } \\
\hline \multirow[t]{2}{*}{ PDS quantity per capita } & $-0.014^{* * *}$ & $-0.020^{* * *}$ & $-0.019^{* * *}$ & $-0.023^{* * *}$ & $-0.015^{* * *}$ \\
\hline & $(0.004)$ & $(0.005)$ & $(0.005)$ & $(0.005)$ & $(0.005)$ \\
\hline \multirow[t]{2}{*}{ PDS quant * Low mkt. cost } & & $0.013^{* *}$ & $0.014^{* *}$ & $0.012^{* *}$ & 0.003 \\
\hline & & $(0.006)$ & $(0.006)$ & $(0.006)$ & $(0.007)$ \\
\hline \multirow[t]{2}{*}{ PDS value per capita } & 0.001 & 0.001 & 0.001 & 0.001 & 0.001 \\
\hline & $(0.001)$ & $(0.001)$ & $(0.001)$ & $(0.001)$ & $(0.001)$ \\
\hline \multirow[t]{2}{*}{ PDS procurement per capita } & -0.000 & 0.000 & -0.000 & -0.000 & -0.000 \\
\hline & $(0.002)$ & $(0.002)$ & $(0.002)$ & $(0.002)$ & $(0.002)$ \\
\hline Observations & 1,112 & 1,112 & 1,112 & 1,110 & 1,112 \\
\hline \multicolumn{6}{|c|}{ Panel C: Ecological Comparative Advantage Index } \\
\hline \multirow[t]{2}{*}{ PDS quantity per capita } & $0.009^{* * *}$ & $0.011^{* * *}$ & $0.009^{* * *}$ & $0.015^{* * *}$ & 0.004 \\
\hline & $(0.003)$ & $(0.004)$ & $(0.003)$ & $(0.004)$ & $(0.004)$ \\
\hline \multirow[t]{2}{*}{ PDS quant ${ }^{*}$ Low mkt. cost } & & $-0.006^{*}$ & -0.002 & $-0.010^{* * *}$ & $0.009^{* * *}$ \\
\hline & & $(0.004)$ & $(0.004)$ & $(0.004)$ & $(0.004)$ \\
\hline \multirow[t]{2}{*}{ PDS value per capita } & -0.000 & 0.000 & -0.000 & -0.000 & 0.000 \\
\hline & $(0.001)$ & $(0.001)$ & $(0.001)$ & $(0.001)$ & $(0.001)$ \\
\hline \multirow[t]{2}{*}{ PDS procurement per capita } & -0.001 & -0.002 & -0.001 & -0.001 & -0.002 \\
\hline & $(0.001)$ & $(0.001)$ & $(0.001)$ & $(0.001)$ & $(0.001)$ \\
\hline Observations & 997 & 997 & 997 & 995 & 997 \\
\hline
\end{tabular}

Standard errors clustered by district in parentheses. ${ }^{* *} \mathrm{p}<0.01,{ }^{* *} \mathrm{p}<0.05,{ }^{*} \mathrm{p}<0.10$. Regressions include district and year fixed effects, and time-varying district level measures of population, fraction of households below the poverty line, real per capita monthly expenditure, openness (distance to agricultural output weighted by highway travel times), rural bank branches per capita, road density, and use of NREGA. PDS quantity per capita (combining rice and wheat) and PDS procurement per capita (reported at the state level) are in monthly KGs. PDS value per capita is the difference between the price paid for PDS grains in the district and the cost of purchasing the same quantities at district median market prices. "Home share" refers to districts with below median median shares of home-produced food for farmers in 1993. "Roads," "Banks," and "Open" refer to districts with above median values of these variables (defined above) in 1993. Ecological comparative advantage combines FAO/GAEZ data on intermediate input potential crop yields with ICRISAT district land allocations (see text for details on index construction). 


\section{A Additional Figures and Tables (For Online Publication)}

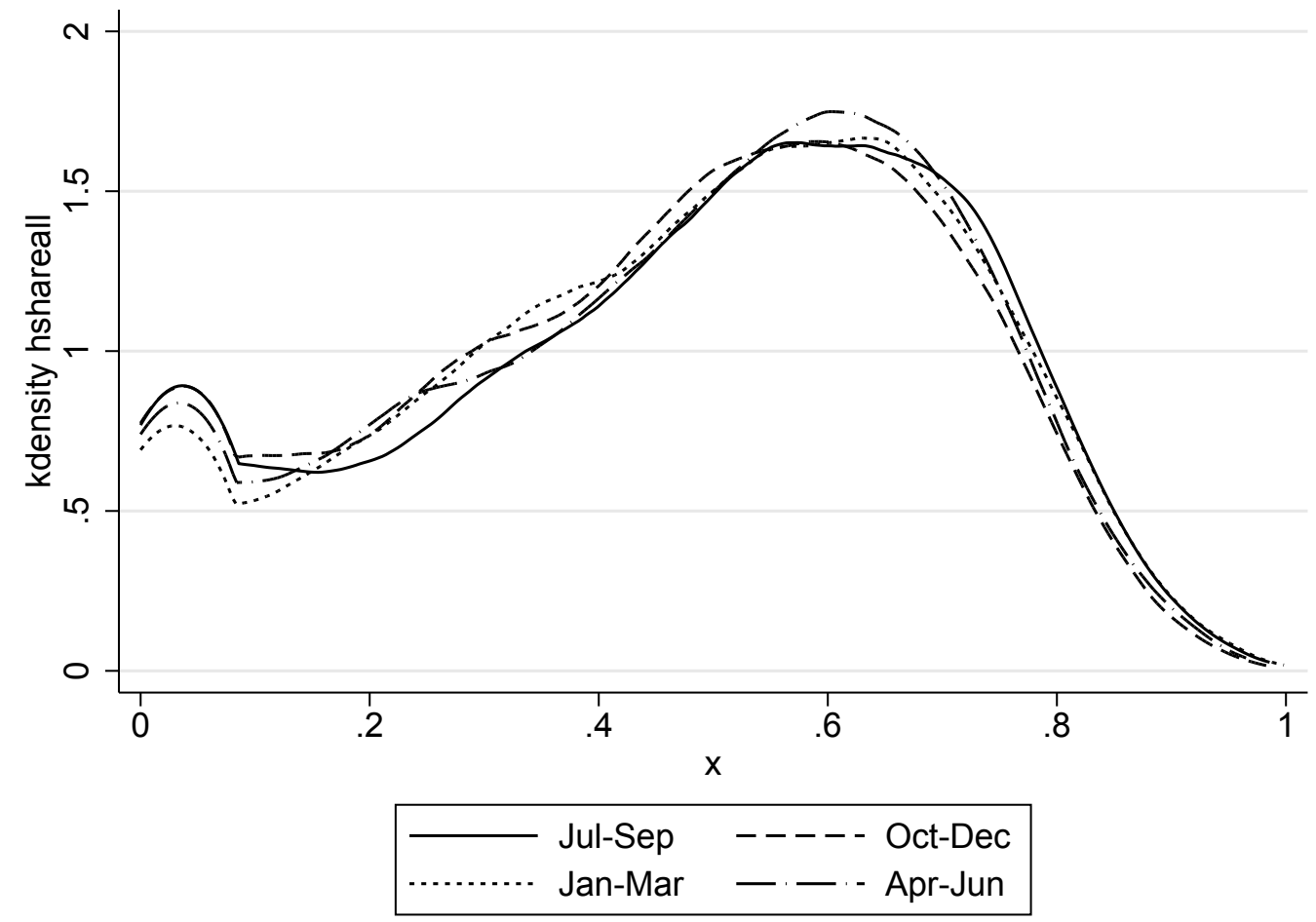

Figure A1: Seasonal variation in home-produced share of consumption for farmers in 1993 (NSS). 

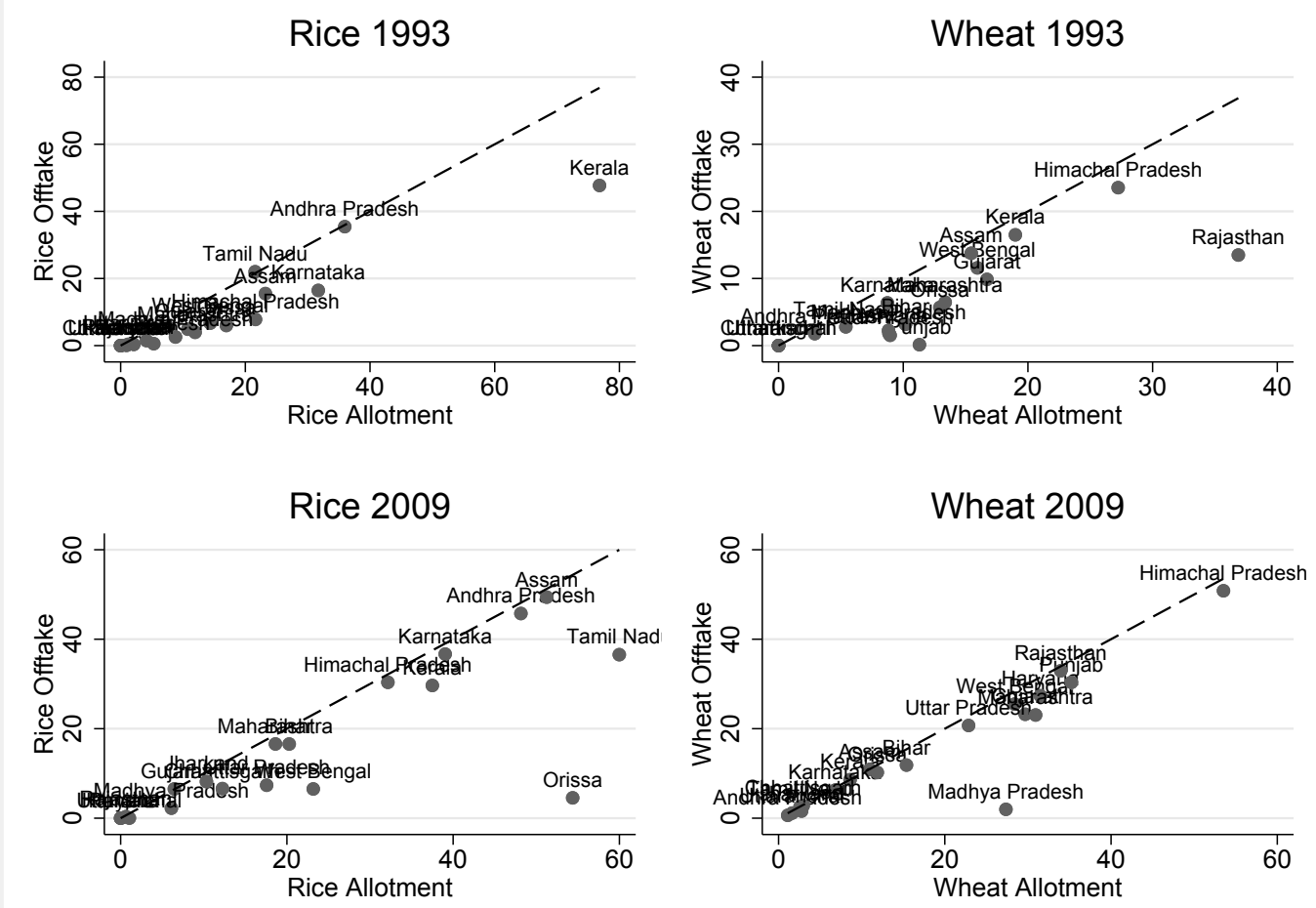

Figure A2: PDS allotment and offtake by state, 1993 and 2009 (all quantities in annual KG per capita). 

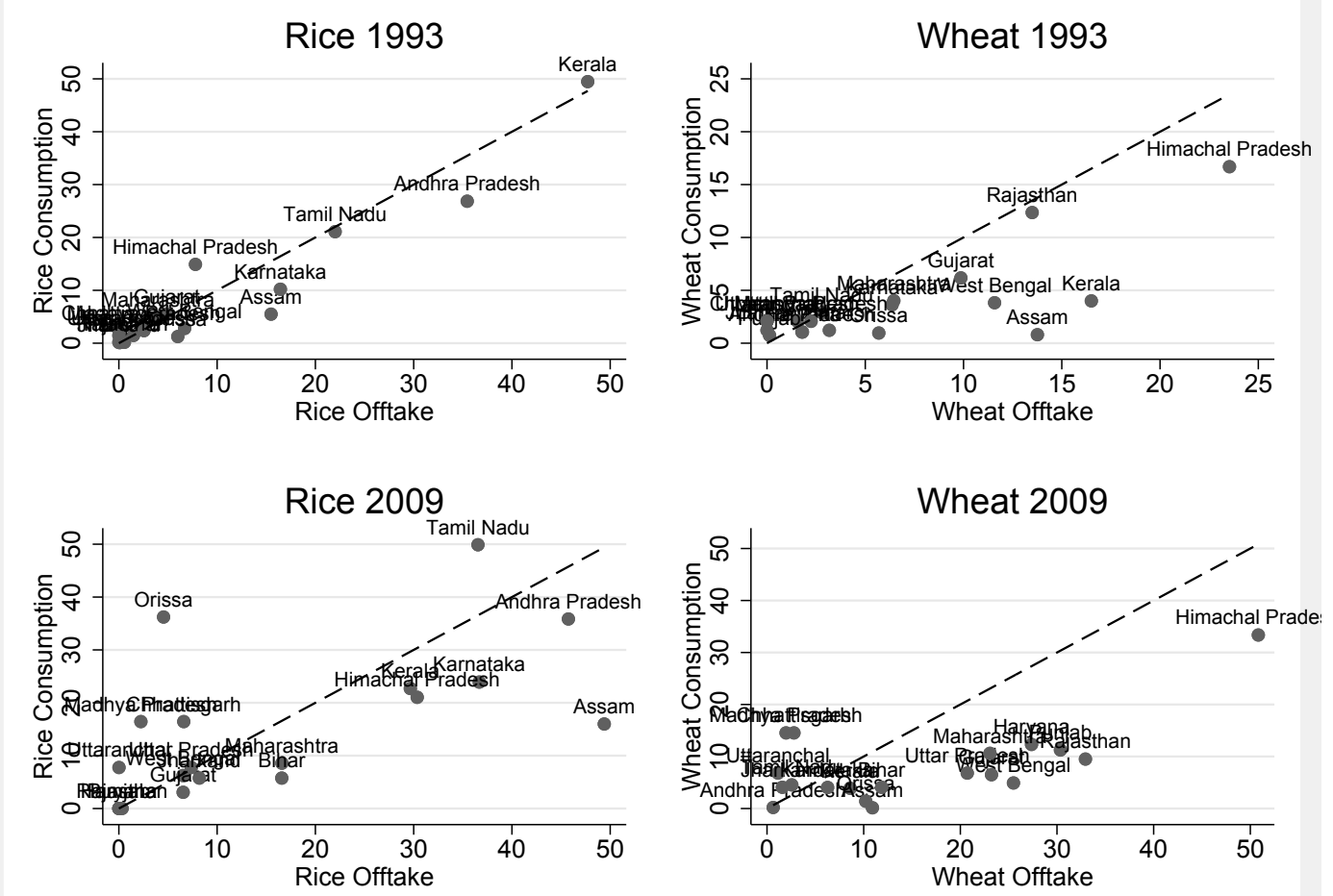

Figure A3: PDS offtake and consumption (NSS) by state, 1993 and 2009 (all quantities in annual KG per capita) 

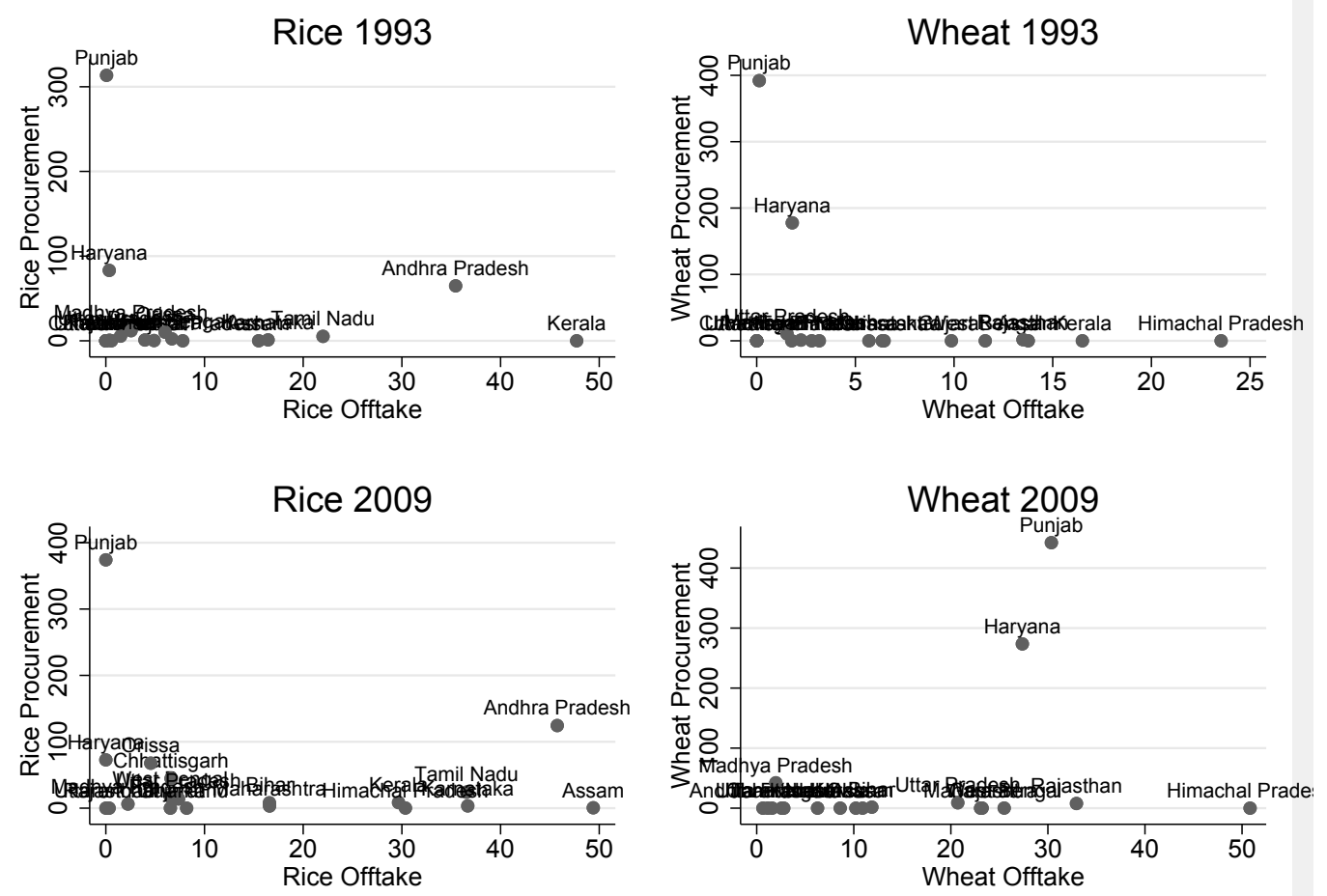

Figure A4: PDS offtake and procurement by state, 1993 and 2009 (all quantities in annual KG per capita) 
Table A1: Household types and importance of farming for own consumption over time in India

\begin{tabular}{lllll}
\hline Household type & Farmer & Ag.laborer & Rural other & Urban \\
\hline \hline & \multicolumn{4}{c}{ Panel A: $1987-88$} \\
Share of households & $\mathbf{0 . 2 7}$ & 0.23 & 0.24 & 0.26 \\
Real p.c. exp. & $\mathbf{3 2 1}$ & 232 & 334 & 508 \\
Land (hectares) & $\mathbf{2 . 1}$ & 0.26 & 0.46 & 0.17 \\
Food share of exp. & $\mathbf{0 . 6 7}$ & 0.68 & 0.66 & 0.62 \\
Share food produced & $\mathbf{0 . 4 5}$ & 0.10 & 0.12 & 0.03 \\
Home share of exp. & $\mathbf{0 . 3 1}$ & 0.07 & 0.08 & 0.02 \\
Number of home produced foods & 4.5 & 1.1 & 1.3 & 0.3 \\
Home rice/wheat & 0.70 & 0.12 & 0.16 & 0.04 \\
PDS rice/wheat & 0.18 & 0.33 & 0.30 & 0.29 \\
\hline & & \multicolumn{2}{c}{ Panel B: $2009-10$} & \\
Share of households & $\mathbf{0 . 2 3}$ & 0.19 & 0.29 & 0.29 \\
Real p.c. exp. & $\mathbf{3 4 7}$ & 254 & 379 & 686 \\
Land (hectares) & $\mathbf{1 . 7}$ & 0.24 & 0.27 & 0.13 \\
Food share of exp. & $\mathbf{0 . 5 6}$ & 0.57 & 0.55 & 0.50 \\
Share food produced & $\mathbf{0 . 3 6}$ & 0.07 & 0.08 & 0.01 \\
Home share of exp. & $\mathbf{0 . 2 0}$ & 0.04 & 0.04 & 0.01 \\
Number of home produced foods & 3.8 & 0.93 & 1.00 & 0.2 \\
Home rice/wheat & 0.66 & 0.11 & 0.12 & 0.03 \\
PDS rice/wheat & 0.32 & 0.64 & 0.42 & 0.27 \\
\hline \hline
\end{tabular}

All data from India National Sample Survey Rounds 50 and 66. Households are classified in NSS based on largest source of income. Real expenditures are in 1993 rupees (deflated using all-India CPI). Reported estimates use sampling weights. 


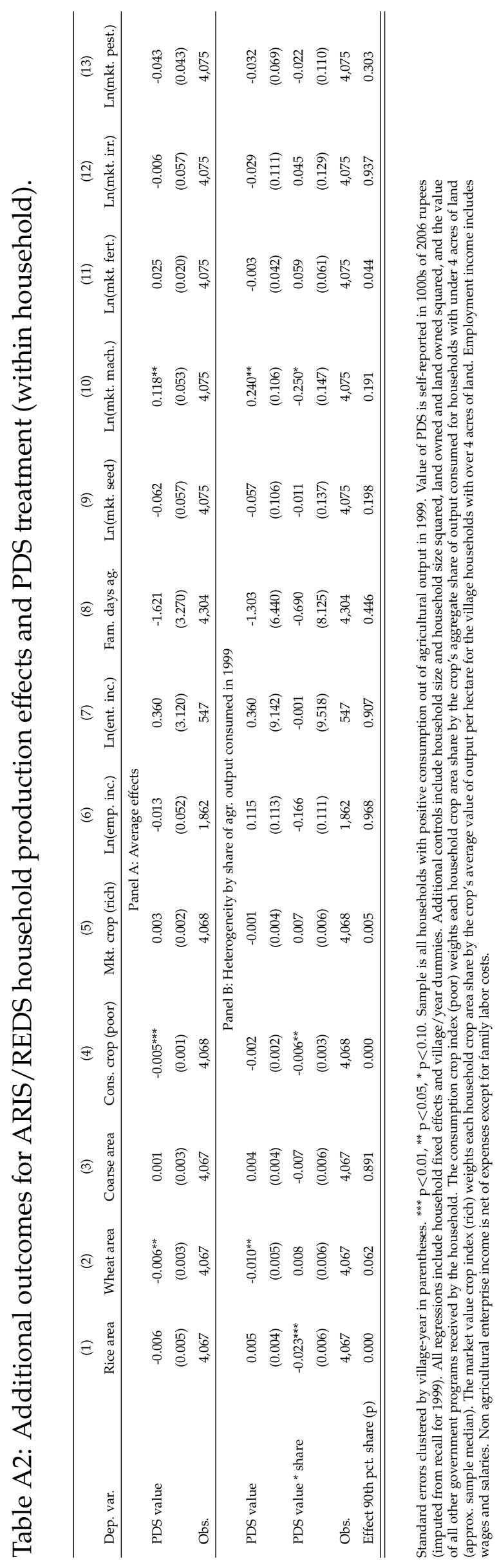


Table A3: ARIS/REDS household production effects and extensive margin effect of PDS treatment (within household).

\begin{tabular}{|c|c|c|c|c|c|c|}
\hline & (1) & (2) & (3) & (4) & (5) & (6) \\
\hline Dep. var. & Area grains & Consumption crop index & Market value crop index & Ln(net agr. inc.) & Ln(net income) & Days agr. work \\
\hline \multicolumn{7}{|c|}{ Panel A: PDS dummy 1999-2006 } \\
\hline \multirow[t]{2}{*}{ PDS dummy } & -0.039 & $-0.008^{*}$ & 0.007 & -0.066 & -0.033 & -36.705 \\
\hline & $(0.026)$ & $(0.005)$ & $(0.012)$ & $(0.105)$ & $(0.107)$ & (29.518) \\
\hline Observations & 4,067 & 4,068 & 4,068 & 4,036 & 4,203 & 4,304 \\
\hline \multicolumn{7}{|c|}{ Panel B: PDS dummy and heterogeneity by share of agr. output consumed in 1999} \\
\hline \multirow[t]{2}{*}{ PDS dummy } & -0.002 & -0.001 & -0.005 & $-0.284^{* *}$ & -0.188 & -25.732 \\
\hline & $(0.047)$ & $(0.009)$ & $(0.022)$ & $(0.138)$ & $(0.145)$ & $(46.652)$ \\
\hline \multirow[t]{2}{*}{ PDS dummy * share cons. } & -0.146 & -0.029 & 0.043 & $0.848^{* *}$ & 0.586 & -41.433 \\
\hline & $(0.121)$ & $(0.021)$ & $(0.055)$ & $(0.431)$ & $(0.543)$ & $(82.281)$ \\
\hline Effect at 90 th pct. share $=0(p)$ & 0.044 & 0.011 & 0.240 & 0.182 & 0.445 & 0.058 \\
\hline Observations & 4,067 & 4,068 & 4,068 & 4,036 & 4,203 & 4,304 \\
\hline
\end{tabular}

Standard errors clustered by village-year. ${ }^{* * *} \mathrm{p}<0.01,{ }^{* *} \mathrm{p}<0.05,{ }^{*} \mathrm{p}<0.10$. Sample is all households with positive consumption out of agricultural output in 1999 . All regressions include household fixed effects and village-year dummies. Additional controls include household size and household size squared, land owned and land owned squared, and the value of all other government programs received by the household. The consumption crop index weights each household crop area share by the crop's aggregate share of output consumed. The market value crop index weights each household crop area share by the crop's average value of output per hectare for the village. Net agricultural income is the total value of crops produced (including consumed those consumed) minus the cost of seeds, fertilizers, pesticides, hired machinery, and irrigation. Net income includes net agricultural income as well as wage and salary income and net income from non-agricultural enterprises. Days agr. work refers to total days of work on the household's farm, including family and hired labor. 
Table A4: Alternative mechanisms for PDS effect: heterogeneity for other government programs and risk (within household). Heterogeneity by share of agr. output consumed in 1999.

\begin{tabular}{|c|c|c|c|c|c|c|c|c|}
\hline & (1) & $(2)$ & (3) & $(4)$ & $(5)$ & (6) & $(7)$ & $(8)$ \\
\hline Dep. var. & Area rice/wheat & Area grains & Cons. crop & Mkt. crop & Ln(net ag. inc.) & Ln(net income) & Days ag. & Ln(mkt. inputs) \\
\hline \multicolumn{9}{|c|}{ Panel A: Including interaction of other government programs with share consumed. } \\
\hline \multirow[t]{2}{*}{ PDS value } & -0.006 & -0.001 & -0.001 & -0.001 & -0.024 & -0.043 & -6.455 & 0.004 \\
\hline & $(0.005)$ & $(0.005)$ & $(0.001)$ & $(0.005)$ & $(0.035)$ & $(0.033)$ & $(7.936)$ & $(0.034)$ \\
\hline \multirow[t]{2}{*}{ PDS value * share consumed } & $-0.015^{* *}$ & $-0.021^{* * *}$ & $-0.003^{* * *}$ & 0.009 & 0.070 & 0.052 & 3.208 & 0.012 \\
\hline & $(0.007)$ & $(0.008)$ & $(0.001)$ & $(0.007)$ & $(0.046)$ & $(0.046)$ & $(10.103)$ & $(0.046)$ \\
\hline \multirow[t]{2}{*}{ Other gov. value } & $-0.003^{* *}$ & -0.000 & -0.000 & $-0.001^{*}$ & $-0.016^{* * *}$ & $-0.008^{*}$ & 0.291 & $-0.019^{* * *}$ \\
\hline & $(0.001)$ & $(0.002)$ & $(0.000)$ & $(0.001)$ & $(0.005)$ & $(0.004)$ & $(1.465)$ & $(0.006)$ \\
\hline \multirow[t]{2}{*}{ Other gov. value * share consumed } & $0.005^{*}$ & -0.001 & 0.000 & 0.002 & $0.034^{* *}$ & 0.010 & -1.951 & $0.042^{* * *}$ \\
\hline & $(0.003)$ & $(0.003)$ & $(0.001)$ & $(0.002)$ & $(0.014)$ & $(0.012)$ & $(2.958)$ & $(0.015)$ \\
\hline Observations & 4,067 & 4,067 & 4,068 & 4,068 & 4,036 & 4,203 & 4,304 & 4,053 \\
\hline PDS effect at 90th pct. share $=0(p)$ & 0.000 & 0.000 & 0.000 & 0.003 & 0.159 & 0.743 & 0.221 & 0.422 \\
\hline Oth. gov. effect at 90th pct. share $=0(p)$ & 0.503 & 0.381 & 0.699 & 0.627 & 0.329 & 0.945 & 0.540 & 0.198 \\
\hline \multicolumn{9}{|c|}{ Panel B: Including interaction of PDS with crop loss risk measure. } \\
\hline \multirow[t]{2}{*}{ PDS value } & -0.005 & -0.002 & -0.001 & -0.001 & -0.019 & -0.049 & -4.896 & 0.007 \\
\hline & $(0.007)$ & $(0.009)$ & $(0.001)$ & $(0.007)$ & $(0.043)$ & $(0.043)$ & $(7.822)$ & $(0.043)$ \\
\hline \multirow[t]{2}{*}{ PDS value * share consumed } & $-0.014^{*}$ & $-0.020^{*}$ & $-0.003^{*}$ & 0.008 & 0.067 & 0.057 & 2.397 & 0.013 \\
\hline & $(0.008)$ & $(0.011)$ & $(0.002)$ & $(0.009)$ & $(0.051)$ & $(0.057)$ & $(10.288)$ & $(0.052)$ \\
\hline \multirow[t]{2}{*}{ PDS value * risk } & -0.000 & -0.000 & -0.000 & 0.000 & 0.000 & 0.001 & -0.330 & 0.000 \\
\hline & $(0.000)$ & $(0.000)$ & $(0.000)$ & $(0.000)$ & $(0.002)$ & $(0.001)$ & $(0.641)$ & $(0.002)$ \\
\hline Observations & 3,984 & 3,984 & 3,985 & 3,985 & 3,953 & 4,111 & 4,207 & 3,970 \\
\hline Effect at 90 th pct. share $/ 50$ th pct. risk $=0(p)$ & 0.000158 & 0.000148 & $2.33 e-06$ & 0.0359 & 0.200 & 0.768 & 0.457 & 0.432 \\
\hline Effect at 50th pct. share/90th pct. risk $=0(p)$ & 0.0199 & 0.222 & 0.0775 & 0.724 & 0.960 & 0.571 & 0.427 & 0.710 \\
\hline
\end{tabular}

Standard errors clustered by village-year in parentheses. ${ }^{* *} \mathrm{p}<0.01,{ }^{* *} \mathrm{p}<0.05,{ }^{*} \mathrm{p}<0.10$. Sample is all households with positive consumption out of agricultural output in 1999. Value of PDS and other government programs is self-reported in 1000s of 2006 rupees (imputed from recall for 1999). Other government programs include: housing support scheme, sanitation support scheme, IAY, ARWSP, Total Sanitation Campaign, Swajaldhara, Samagra Yawaas Yojana, SGRY, SGSY, ICDS, Social Security Pension, Mid-day meal program, Business Support Program, Food for work program, PMGY, Employment Guarantee Scheme, Credit cum subsidy scheme, women Pension, Mid-day meal program, Business Support Program, Food for work program, PMGY, Employment Guarantee Scheme, Credit cum subsidy scheme, women
centric programs and scholarships. "Risk" is measured using the total expenditures and losses (in 2006 rupees) incurred by the household between 1999 and 2006 from crop loss, pests, wells drying up, drought at the village level and crop loss, price increases, irrigation well drying up at the household level. All regressions include household fixed effects and village/year dummies. Additional controls include household size and household size squared, land owned and land owned squared, and the value of all other government programs received by the household. The consumption crop index weights each household crop area share by the crop's aggregate share of output consumed. The market value crop index weights each household crop area share by the crop's average value of output per hectare for the village. Net agricultural income is the total value of crops produced (including consumed those consumed) minus market purchases of inputs (seeds, fertilizers, pesticides, hired machinery, and irrigation). Net income includes net agricultural income as well as wage and salary income and net income from non-agricultural enterprises. Days agr. work refers to total days of work on the household's farm, including family and hired labor. 
Table A5: Rice and wheat market prices: heterogeneity in district-level effects of PDS expansion (rural India 1993-2009)

\begin{tabular}{|c|c|c|c|c|c|c|c|c|}
\hline \multirow{3}{*}{$\begin{array}{l}\text { Dep. var. } \\
\text { Low marketization cost }\end{array}$} & (1) & (2) & (3) & (4) & (5) & (6) & (7) & (8) \\
\hline & \multicolumn{4}{|c|}{ NSS market price of rice } & \multicolumn{4}{|c|}{ NSS market price of wheat } \\
\hline & Home share & Roads & Banks & Open & Home share & Roads & Banks & Open \\
\hline \multirow{2}{*}{ PDS quantity per capita } & $-0.053^{* * *}$ & $-0.050^{* * *}$ & $-0.053^{* * *}$ & $-0.036^{* * *}$ & $-0.027^{* * *}$ & $-0.023^{* * *}$ & $-0.044^{* * *}$ & $-0.019^{*}$ \\
\hline & $(0.008)$ & $(0.009)$ & $(0.010)$ & $(0.008)$ & $(0.009)$ & $(0.008)$ & $(0.011)$ & $(0.010)$ \\
\hline \multirow[t]{2}{*}{ PDS quant ${ }^{*}$ Low mkt. cost } & $0.024^{* * *}$ & 0.013 & $0.015^{*}$ & $-0.023^{* * *}$ & 0.006 & -0.006 & $0.026^{* *}$ & -0.012 \\
\hline & $(0.008)$ & $(0.008)$ & $(0.008)$ & $(0.008)$ & $(0.012)$ & $(0.015)$ & $(0.012)$ & $(0.013)$ \\
\hline \multirow[t]{2}{*}{ PDS value per capita } & $0.012^{* * *}$ & $0.012^{* * *}$ & $0.013^{* * *}$ & $0.012^{* * *}$ & $0.006^{* * *}$ & $0.006^{* * *}$ & $0.006^{* * *}$ & $0.006^{* * *}$ \\
\hline & $(0.002)$ & $(0.002)$ & $(0.002)$ & $(0.002)$ & $(0.002)$ & $(0.002)$ & $(0.002)$ & $(0.002)$ \\
\hline \multirow[t]{2}{*}{ PDS procurement per capita } & -0.002 & -0.003 & -0.003 & -0.003 & $0.010^{* *}$ & $0.010^{* *}$ & $0.010^{* *}$ & $0.011^{* *}$ \\
\hline & $(0.003)$ & $(0.003)$ & $(0.003)$ & $(0.003)$ & $(0.004)$ & $(0.004)$ & $(0.004)$ & $(0.004)$ \\
\hline Observations & 1,112 & 1,112 & 1,110 & 1,112 & 1,112 & 1,112 & 1,110 & 1,112 \\
\hline
\end{tabular}

Standard errors clustered by district in parentheses. ${ }^{* *} \mathrm{p}<0.01,{ }^{* *} \mathrm{p}<0.05,{ }^{*} \mathrm{p}<0.10$. Regressions include district and year fixed effects, and time-varying district level measures of population, fraction of households below the poverty line, real per capita monthly expenditure, openness (distance to agricultural output weighted by highway travel times), rural bank branches per capita, road density, and use of NREGA. PDS quantity per capita and PDS procurement per capita (reported at the state level) are in monthly KGs. PDS value per capita is the difference between the price paid for PDS grains in the district and the cost of purchasing the same quantities at district median market prices. "Home share" refers to districts with below median share of self-produced food by farmers. "Roads," "Banks" and "Open" refer to districts with above median values of these variables defined above.

Table A6: NSS aggregate consumption: effects of PDS expansion (rural India 19932009)

(1)

\begin{tabular}{lccc} 
VARIABLES & Rice/wheat cons. p.c. & Home rice/wheat cons. p.c. & Mkt. rice/wheat cons. p.c. \\
\hline PDS quantity per capita & $0.196^{* *}$ & $-0.440^{* * *}$ & $-0.365^{* * *}$ \\
& $(0.089)$ & $(0.080)$ & $(0.095)$ \\
PDS value per capita & -0.007 & 0.002 & -0.009 \\
& $(0.020)$ & $(0.017)$ & $(0.021)$ \\
PDS procurement per capita & -0.043 & 0.038 & $-0.081^{* *}$ \\
& $(0.037)$ & $(0.035)$ & $(0.036)$ \\
Observations & 1,112 & 1,112 & 1,112 \\
\hline \hline
\end{tabular}

Robust standard errors (clustered by district in Panel B) in parentheses. ${ }^{* * *} \mathrm{p}<0.01,{ }^{* *} \mathrm{p}<0.05,{ }^{*} \mathrm{p}<0.10$. Regressions include district and year fixed effects, and time-varying district level measures of population, fraction of households below the poverty line, real per capita monthly expenditure, openness (distance to agricultural output weighted by highway travel times), rural bank branches per capita, road density, and share of households using NREGA. All quantities measured in kilograms per month per capita. PDS value per capita is the difference between the price paid for PDS grains in the district and the cost of purchasing the same quantities at district median market prices. 
Table A7: Robustness for average district-level effects of PDS expansion (rural India 1993-2009)

\begin{tabular}{|c|c|c|c|c|c|c|c|}
\hline & $(1)$ & $(2)$ & (3) & $(4)$ & $(5)$ & (6) & (7) \\
\hline VARIABLES & Rice price & Rice output & Wheat price & Wheat output & Frac. farmer & Home share food & Eco. comp. adv. \\
\hline \multicolumn{8}{|c|}{ Including district linear time-trends } \\
\hline \multirow[t]{2}{*}{ PDS quantity per capita } & $-0.041^{* * *}$ & $-0.077^{*}$ & -0.001 & -0.054 & $-0.022^{* *}$ & $-0.015^{*}$ & -0.001 \\
\hline & $(0.012)$ & $(0.040)$ & $(0.012)$ & $(0.039)$ & $(0.009)$ & $(0.008)$ & $(0.005)$ \\
\hline \multirow[t]{2}{*}{ PDS value per capita } & $0.014^{* * *}$ & 0.007 & 0.001 & $-0.006^{* *}$ & 0.001 & 0.001 & 0.001 \\
\hline & $(0.003)$ & $(0.008)$ & $(0.003)$ & $(0.003)$ & $(0.002)$ & $(0.002)$ & $(0.001)$ \\
\hline \multirow[t]{2}{*}{ PDS procurement per capita } & $-0.001^{* * *}$ & 0.002 & $0.001^{*}$ & $0.011^{* * *}$ & 0.003 & -0.004 & -0.001 \\
\hline & $(0.000)$ & $(0.001)$ & $(0.001)$ & $(0.002)$ & $(0.004)$ & $(0.003)$ & $(0.002)$ \\
\hline Observations & 1,112 & 1,112 & 1,112 & 1,098 & 1,112 & 1,112 & 997 \\
\hline \multicolumn{8}{|c|}{ Including state-year fixed effects } \\
\hline \multirow[t]{2}{*}{ PDS quantity per capita } & $-0.066^{* * *}$ & $-0.122^{* * *}$ & 0.002 & -0.007 & $-0.022^{* *}$ & $-0.024^{* * *}$ & -0.005 \\
\hline & $(0.012)$ & $(0.035)$ & $(0.008)$ & $(0.034)$ & $(0.009)$ & $(0.007)$ & $(0.005)$ \\
\hline \multirow[t]{2}{*}{ PDS value per capita } & $0.016^{* * *}$ & 0.002 & 0.001 & -0.003 & -0.002 & 0.000 & $0.003^{* *}$ \\
\hline & $(0.003)$ & $(0.006)$ & $(0.002)$ & $(0.004)$ & $(0.003)$ & $(0.002)$ & $(0.001)$ \\
\hline Observations & 1,112 & 1,112 & 1,112 & 1,098 & 1,112 & 1,112 & 997 \\
\hline
\end{tabular}

Robust standard errors (clustered by district in Panel B) in parentheses. ${ }^{* * *} \mathrm{p}<0.01,{ }^{* *} \mathrm{p}<0.05,{ }^{*} \mathrm{p}<0.10$. Regressions include district and year fixed effects, and timevarying district level measures of population, fraction of households below the poverty line, real per capita monthly expenditure, openness (distance to agricultural output weighted by highway travel times), rural bank branches per capita, road density, and share of households using NREGA. PDS quantity per capita and state-level PDS procurement (separately in columns 1-4, combining rice and wheat for columns 5-7) are in monthly KGs.

Table A8: Agricultural inputs: district-level effects of PDS expansion (rural India 1993-2009)

\begin{tabular}{lccccc}
\hline & $(1)$ & $(2)$ & $(3)$ & $(4)$ & $(5)$ \\
VARIABLES & Ln(fertilizer) & Share irrigated & Ln(wells) & Ln(livestock) & Ln(tractors) \\
\hline PDS quantity per capita & -0.011 & -0.004 & $-0.089^{*}$ & 0.009 & $-0.108^{* *}$ \\
& $(0.026)$ & $(0.004)$ & $(0.047)$ & $(0.030)$ & $(0.046)$ \\
PDS value per capita & 0.004 & 0.000 & $0.023^{* * *}$ & 0.005 & $0.085^{* * *}$ \\
& $(0.005)$ & $(0.001)$ & $(0.007)$ & $(0.016)$ & $(0.017)$ \\
PDS procurement per capita & 0.005 & $0.002^{*}$ & -0.007 & -0.002 & $-0.038^{* * *}$ \\
& $(0.006)$ & $(0.001)$ & $(0.007)$ & $(0.004)$ & $(0.011)$ \\
Observations & 1,111 & 950 & 943 & 814 & 684 \\
\hline \hline
\end{tabular}

Standard errors clustered by district in parentheses. ${ }^{* * *} \mathrm{p}<0.01,{ }^{* *} \mathrm{p}<0.05,{ }^{*} \mathrm{p}<0.10$. Regressions include district and year fixed effects, and time-varying district level measures of population, fraction of households below the poverty line, real per capita monthly expenditure, openness (distance to agricultural output weighted by highway travel times), rural bank branches per capita, road density, and use of NREGA. PDS quantity per capita (combining rice and wheat) and PDS procurement per capita (reported at the state level) are in monthly KGs. PDS value per capita is the difference between the price paid for PDS grains in the district and the cost of purchasing the same quantities at district median market prices. All input data are quantities recorded from ICRISAT district data set (fertilizer is sum of nitrogen, phosphorus and potash). 
Table A9: State-level regressions including PDS offtake (India 1993-2009)

\begin{tabular}{lcccccc}
\hline & $(1)$ & $(2)$ & $(3)$ & $(4)$ & $(5)$ & $(6)$ \\
Dep. var. & Rice/wheat output per capita & Fraction of households self-employed in agriculture \\
\hline PDS quantity per capita & $-0.141^{* *}$ & & $-0.098^{* *}$ & -0.007 & -0.006 \\
& $(0.053)$ & & $(0.048)$ & $(0.008)$ & & $(0.015)$ \\
PDS offtake per capita & & -0.045 & -0.027 & & -0.003 & -0.002 \\
& & $(0.051)$ & $(0.047)$ & & $(0.007)$ & $(0.007)$ \\
PDS procurement per capita & 0.027 & 0.019 & 0.025 & 0.002 & 0.001 & 0.002 \\
& $(0.019)$ & $(0.018)$ & $(0.018)$ & $(0.003)$ & $(0.003)$ & $(0.003)$ \\
PDS value per capita & & & -0.008 & & & 0.000 \\
& & & $(0.009)$ & & & $(0.003)$ \\
Observations & 64 & 64 & 64 & 64 & 64 & 64 \\
\hline \hline
\end{tabular}

Robust standard errors in parentheses. ${ }^{* * *} \mathrm{p}<0.01,{ }^{* *} \mathrm{p}<0.05,{ }^{*} \mathrm{p}<0.10$. Regressions include state and year fixed effects, and time-varying state level measures of population, fraction of households below the poverty line, and real per capita monthly expenditure. All quantities in monthly kilograms. PDS value per capita is the quantity of PDS grains multiplied by the difference between median state market and PDS prices. 